\title{
Franklin en el Mundo Hispano
}

\author{
“...esperamos que nuestra América \\ siga produciendo lo que es acaso su \\ más alta característica: los hombres \\ magistrales." \\ Pedro Henríquez Ureña. \\ "...una armoniosa multitud humana." \\ Carl Van Doren.
}

\section{Préambulo}

EN la historia de las relaciones culturales entre el mundo hispánico y el mundo anglosajón americano, Franklin es el único que se destaca como personaje vivo y humano en la galería de los grandes próceres de nuestra epopeya independista. Para el gran pueblo hispano, al menos, la mayoría de los próceres se funden en un único ser, símbolo de las aspiraciones libertarias y democráticas de los rebeldes colonos británicos del Norte. Con la excepción de Wáshington, más tarde celebrado como "el primero en la guerra, el primero en la paz, y el primero en el corazón de sus compatriotas", y de Jéfferson - renombrado como el autor de la "Declaración de Independencia", los demás-Patrick Henry, Thomas Paine, James Hamilton, John Adams- se pierden en la anonimidad colectiva de héroes nacionales. Franklin, al contrario, tocó la conciencia hispánica en toda la elaboración de una fama debida a sus largos contactos personales en Francia e Inglaterra, donde las múltiples facetas de su genio y de su carácter amenazaron colocarle en un plano ya casi legendario. Además, 
fue el único de aquella generación de proto-hombres a ser conocido no sólo como panfletista político, sino también como escritor de estudios de variada índole científica, sociológica y moral. Y ya antes de finalizar el siglo XVIII, su propia autobiografía fue leída por todo el mundo occidental como la del hombre más representativo de la joven república americana.

No fue hasta el segundo tercio del siglo XIX que la primera generación literaria nuestra - Irving, Ticknor, Cooper, Bryant, Longfellow, Prescott-empezó a ofrecerle verdadera competencia a Franklin entre el público lector de habla española y portuguesa. Cabe notar, además, que la popularidad de algunos de esa generación, especialmente de los Irving y los Prescott y mayormente en cuanto a España toca, se debió en gran parte a su dedicado hispanismo y a las íntimas amistades formadas en la misma Península. Por razones inherentes a la época y a las mismas circunstancias de su propia vida, Franklin no se distinguió como hispanista y tampoco le fue dado ni viajar ni vivir en ningún país hispano. Sabemos, empero, que desde muy joven, ya en 1733, aquel autodidacta, que creía firmemente en la eficacia y hasta en la necesidad de hablar varios idiomas, se puso a aprender el español, con miras, sin duda alguna, de que algún día le resultaría útil tal conocimiento. Años después, como uno de los fundadores (1749), Franklin propuso que se incluyera el estudio del español en el programa de la Philadelphia Academy, la que más tarde vino a ser la Universidad de Pennsylvania. $Y$ aunque nunca llegó a dominarlo como lengua hablada, debió seguir interesándose tanto por la cultura como por el idioma de España en vista de que toda su vida se empeñó en obtener impresos en español. Y, finalmente, allí está el nombre "Junto". con que bautizó la sociedad de diez amigos fundada en 1727, es decir, aun antes de que iniciara el estudio metódico del idioma. El "Junto", como es sabido, se transformó en la célebre American Philosophical Society, la cual mantuvo Franklin por unos treinta años y de la cual fue presidente desde 1769 hasta 1790, año de su muerte. Esta sociedad, la más vieja institución científica del país, fue la primera también que estableció y mantuvo relaciones estrechas con el mundo hispánico. 
Tal interés por España de parte de Franklin fue lógico y hasta inevitable en aquellos momentos decisivos de nuestra historia nacional cuando el futuro dependía, en gran parte, de la simpatía y del apoyo efectivo que nuestros antepasados pudieran obtener de las naciones tradicionalmente enemigas de Inglaterra. España, por su dominio de vastas regiones americanas, algunas de las cuales figuraban ya como elemento activo en el juego diplomático internacional de Inglaterra y más tarde como estorbo irritante al movimiento expansionista del país, no pudo menos de pedir la atención imperiosa y constante de los más capacitados estadistas americanos de la época. De todos aquellos responsables de formular y establecer las bases del "gran experimento" y de guiar nuestros primeros pasos internacionales, no cabe duda de que tanto dentro como fuera del país, el más popular y el más querido fue el venerable viejo en quien el mundo exterior creyó ver reunidas todas las características que le distinguían ya como el auténtico prototipo del joven pueblo americano. Más que ningún otro, Franklin reunía cualidades y realizaba proyectos que en su conjunto representaban el esfuerzo común de todos sus compatriotas. Por eso, muchas veces la presencia y el mensaje de Franklin iban entrañablemente unidos con los de sus contemporáneos, séanlos Wáshington, Jéfferson, Paine, por representar ellos la más alta expresión de una sola faceta del múltiple carácter y de la variadísima labor del patriarca de toda aquella fructífera generación.

El Leonardo Americano

\author{
"Eripuit coelo fulmen sceptrumque \\ tyrannis."
}

Turgot.

Desde mediados del siglo, a raíz de sus primeros experimentos en electricidad y de haber lanzado su histórica cometa, la fama del nuevo Prometeo que "robó el rayo a los cielos" pronto reverberó por todo el Occidente. En 1753, la Royal Society of London le honró con su medalla de oro, acto seguido 
de r'epetidos elogios y honores que le prodigaron los más afamados genios y las más grandes instituciones científicas y culturales del mundo. En 1759, la Universidad de San Andrés, Escocia, le otorgó el grado de doctor. En 1762, le fue concedido el mismo alto grado honorario por Oxford, y en años posteriores por las de Dublin y Edinburgh. No pudo contenerse la avalancha de homenajes en honor de un genio fabuloso a quien el mito creciente atribuía toda clase de invenciones nuevas y cuyo nombre venía siendo para el mundo de entonces palabra ya corriente y casera o, como se dice en inglés, "a household word". Y su nombre fue respetado igualmente por todos los hombres de ciencia de su tiempo, los cuales le votaron miembro honorario de casi todas las Reales Sociedades y las academias nacionales de Inglaterra, Francia, Suecia, Italia y Rusia. Por eso, no era sino lógico y natural que también España, en 1784, reconociera su mérito al nombrarle el primer correspondiente americano de la Real Academia de la Historia.

Sería aventurado decir, por faltar datos concretos para el caso, cuándo y cómo el nombre de Franklin primero captó la atención de los peninsulares, y más específicamente de los científicos españoles. Hay, sin embargo, datos convincentes que testimonian su presencia en las colonias veinte años antes de haber sido honrado por la Madre Patria. Sabemos, por ejemplo, que en 1764 el jesuita Benito de Riba, profesor en la Córdoba del lejano virreinato del Río de la Plata, identificó el nombre de Franklin con el de Descartes y Newton. ${ }^{1}$ Que ya por varios años la fama de Franklin como científico iba recorriendo las aulas y las bibliotecas de los jesuitas y que sus investigaciones eran objeto de estímulo y de estudio, es fácil comprobar mediante un examen de los archivos universitarios. Los expedientes, las tesis y los discursos académicos revelan que hubo un gran interés en todos los problemas relacionados con la electricidad -reflejo, claro está, del movimiento científico que coronaba la vida intelectual tanto de la Península como de las Américas durante el último tercio del ocaso colonial-y un aprecio general de la contribución hecha por

1 V. Guillermo Furlong, "The influence of Benjamin Franklin in the River Plate area before 1810". The Americas, XII (enero 1956), p. 259. 
Franklin no sólo en el terreno de la teoría científica, sino también en el de las invenciones prácticas y útiles. Hubo otros, pues, en el Río de la Plata, tales como Melchor Fernández y Valentín Gómez, entusiasmados admiradores del "físico" de Philadelphia, que dentro y fuera de las aulas explicaban y defendían sus especulaciones científicas. En 1782, al permitir a sus alumnos decidir cuál de las dos teorías sobre el rayo eléctrico entonces en boga, la de Nollet y la de Franklin era la mejor, Fernández se mostró partidario de la del último. Y allá por 1788, Gómez hablaba a los suyos en física de los maravillosos fenómenos eléctricos tan admirablemente descritos por Franklin.2

Contemporáneamente con estos "discípulos" rioplatenses hubo otros en casi todos los centros universitarios americanos que, como científicos y catedráticos, divulgaban las teorías de Franklin y dirigían tesis inspiradas en ellas. El archivo de la Universidad de Caracas descubre como tales, por ejemplo, a José Timoteo Llamozas y a José Antonio Bolívar. ${ }^{3}$ En el Perú hubo el "gigante intelectual", Hipólito Unánue (1755-1833), quien, como humanista, periodista, legislador, sabio maestro, eugenista, y "Padre de la medicina en América", ofrece un paralelo extraordinario con Franklin, siendo, como éste, no un hombre solo, sino "una armoniosa multitud humana".4 En el "Elogio de don José de Urrutia", Unánue expresa así su admiración por Franklin y por la obra de sus hermanos próceres: "Pero, ¿qué importa si los anima el espíritu de Franklin? Franklin, cuya sabiduría ha llegado a encadenar los rayos tremendos 'del cielo, armará la diestra de Wáshington, el norteamericano, con los más fuertes de la tierra." ${ }^{5}$ Otro paralelo interesante podría hacerse del fecundo inventor Franklin con el limeño José Moreno, cuyos numerosos diseños e instrumentos por él mismo hechos para sus propios alumnos,

2 Ibid., pp. 259-260.

3 V. Carraciolo Parra, Filosofía universitaria venezolana, 1788-1821. Caracas, 1934. Citado por Furlong, op. cit., p. 260.

4 V. Luis C. Infante, "Paralelo entre Benjamín Franklin y don Hipólito Unánue", IPNA, 29 (1955), pp. 30-33.

5 V. Estuardo Núñez, "Hipólito Unánue y la cultura inglesa y norteamericana", IPNA, 28 (1955), p. 23. 
asombraron, según Unánue, a todo viajero europeo que llegara a aquella ciudad, donde ni el uno ni el otro se cansará jarnás de hablar del genio Franklin. ${ }^{6}$ Y, finalmente, hay que recordar al político y escritor peruano "multánime", Manuel Lorenzo de Vidaurre (1773-1841), que hablaba de Franklin como el "Leonardo americano", viendo en él "un portento extraordinario de conocimiento, pero no... como filósofo de minorías, sino como el sabio benefactor del pueblo y de la humanidad". 7

Como dinámico hijo de la Ilustración, el economista político chileno Manuel de Salas no pudo menos de venerar a todos aquellos cuya labor científica también sirvió para liberar a América del vasallaje intelectual y cultural del viejo mundo. Hubo que acabar con aquel mito de la dependencia colonial y a ese fin -declaró en 1801-contribuyeron las obras y la justa fama de los Peralta, Franklin y Molina, en cuyas manos la astronomía, la electricidad y la historia habian alcanzado una significación nueva. ${ }^{8}$

Fue en México, empero, donde más hondamente parece haberse arraigado la fama de Franklin, fama debida en gran parte a la divulgación de su nombre y de su obra realizada por su devoto discípulo el padre y doctor José Antonio Alzate Ramírez (1729-1799). Alzate escribió y dictó conferencias sobre casi todos los ramos de la ciencia de su tiempo. Tal interés enciclopédico, característico de parte de todos los verdaderos filósofos naturalistas de la época, se ve manifiesto en su aprecio y en sus traducciones - de las primeras en lengua castellana-- ${ }^{9}$ de la obra de Franklin, admiración que trans-

6 V. John Tate Lanning, "The reception of the Enlightenment in Latin América", Latin America and the Enlightennent. New York: Appleton-Century, 1942, p. 81.

7 V. Estuardo Núñez, "Franklin en América hispana", IPNA, 29 (1955), p. 17.

8 Escritos de don Manuel de Salas. I. 608. Citado por Harry Bernstein, "Some Inter-American aspects of the Enlightenment", Latin America and the Enligbtenment, pp. 55-56.

9 V. Alzate, "Breve elogio de Benjamín Franklin", Gaceta de literatura de México, 13 diciembre 1790 , pp. 74-77, donde dice: ". . paso a dar traducido uno u otro fragmento, y continuaré en los venideros, porque no veo tenemos en castellano de las obras de Franklin sino uno u otro pequeño fragmento". No sé de estos pequeños fragmentos a que se refiere. A base de unas notas, y del comentario que 
mitió al selecto público lector principalmente a través de la Gaceta de literatura de México, de la cual era redactor. En las páginas de la Gaceta correspondientes a los años 17901793, Alzate tradujo extractos de Franklin sobre experimentos relativos al calor que comunican los rayos del sol, a la sensación que los nervios ópticos reciben de los objetos luminosos, a los efectos del aceite sobre el agua turbulenta, al poder que tienen los vegetales para purificar el aire corrompido por los animales, al frío que se experimenta por la evaporación de los licores, etc.10 Al confesar a los suscritores que le haría falta mucho papel para tratar de las investigaciones e invenciones de Franklin, ${ }^{11}$ reveló el aspecto de su labor que más le atraía a él como "físico" práctico y abnegado, aspecto que ensalza en el artículo necrológico, "Breve elogio de Benjamín Franklin", que escribió al recibir la noticia de la muerte del "nuevo Prometeo que robó el fuego al cielo" ${ }^{12}$ :

Sus descubrimientos forman en la física verdadera, en la que es útil a los hombres, una época memorable. No era de aquellos físicos que erizan sus obras con cálculos penosos que alejan a los principiantes del santuario de la física; la experiencia, la observación, los ejemplos eran las fuentes de que deducía Franklin sus descubrimientos, y por esto los acechos de la envidia y de la cavilosidad jamás triunfaron de su mérito. ${ }^{13}$

No cabe duda de que "el nuevo Prometeo americano" llegó a ser conocido y respetado también en otros rincones de la América de aquel entonces: en Cuba, en el Brasil, en Guatemala, aunque falta en tal o cual caso la documentación concreta para probarlo. El hecho de que Mariano Padilla hablara de las investigaciones de Franklin en el campo de la electri-

sigue, estas "primeras" traducciones debieron ser todas del francés: "Qué trabajo me ha costado no traducir, sino exponer el sentido legítimo que presentó el autor! El traductor francés confundió las ideas". V. Gacetas de literatura de México (Puebla, 1831), pp. 128-136, reimpreso de la Gaceta correspondiente a un número no determinado entre el 9 de abril y el 28 de mayo de 1793.

10 V. Bibliografía, post, p. 360.

11 V. Gaceta de literatura de México, I (1789), pp. 22, 50. Citado por Bernstein, Origins of Inter-American interest, 1700-1812. Philadelphia: University of Pennsylvania Press, 1945, p. 64.

12 Gaseta de literatura de México, 20 febrero 1790.

13 Gaceta de literatura de México, 13 diciembre 1790, pp. 74.79. 
cidad, en el "Discurso para la apertura de las clases de la Pontificia Universidad de San Carlos de Guatemala" el día 16 de octubre de $1842,{ }^{14}$ no debe ser interpretado como indicación de que el nombre de Franklin sólo tuviera resonancia atrasada allá en Guatemala. Más de medio siglo antes hubo contactos directos e indirectos, por ejemplo, entre ilustres hijos y científicos de la Universidad de San Carlos y el College of Philadelphia. El Dr. José Felipe Flores, médico honorario de la Corte, había sido autorizado por la Corona para seguir estudios avanzados en la ciudad de Franklin, donde, en 1797, se puso en contacto con los más distinguidos científicos de la época, entre ellos el eminente médico Benjamín Smith Barton, del College de Philadelphia. Posteriormente, en 1801 y 1802, la Gaceta de Guatemala acogió y divulgó los tratados y las ideas de Barton, y también los de sus colegas Rush y Coxe. Para dar el debido realce a este detalle de comunicación científica interamericana, urge indicar que el Dr. José Felipe Flores era colega y discípulo del Padre Goicoechea, uno de los más célebres académicos guatemaltecos de su tiempo, y aun en el Brasil, donde faltó universidad y donde las academias sólo sirvieron de guardianes de la tradición literariohistórica lusitana, la Sociedade Scientífica do Rio de Janeiro, fundada en 1772 , bien pudiera haber sido fructífero punto de contacto y de entrada para el nombre y la obra de Franklin.

Las universidades y las distintas gacetas nacionales contribuyeron mucho, pues, al rápido intercambio de ideas y publicaciones de la época. En tal intercambio no pudo faltar ni el nombre ni el espíritu del periodista e impresor de Philadelphia, renombrado fundador y presidente de la American Philosophical Society. Ya antes de 1790, la American Philosophical Society empezó a establecer canje de publicaciones con las academias y universidades hispanas, y también con las nuevas instituciones culturales que florecieron por todo el mundo español desde que se fundó la primera Sociedad de Amigos del País en España en 1766. No sólo hubo canje de publicaciones, sino también contactos epistolares y honores conferidos sobre miembros de una y otra sociedad, como en el

14 Guatemala: Imprenta de la Paz, 1842. 
caso del honor concedido a Franklin por la Real Academia de la Historia en 1784, honor que en 1801 la American Philosophical Society confirió al destacado botánico Alejandro Ramírez, su primer correspondiente científico de la América hispana. Sería difícil exagerar las repercusiones de tal acto en el caso de $\tan$ distinguido personaje, quien, entre otros títulos, lucía también, en la labor que le llevaba por tierras del Caribe y de la América Central, los de primer secretario de la Junta de Guatemala y socio de la Real Academia de la Historia. ${ }^{15} \mathrm{Y}$, finalmente, no hay que olvidar que la América toda de aquellos años fue invadida por científicos europeos que dieron un impulso incalculable a tales estudios y que sirvieron como un nexo vital entre las ideas y los hombres de todo el mundo occidental. También, pues, en el mundo hispánico de fines del siglo XVIII, como lo había afirmado John Adams con respecto a Europa allende los Pirineos, la reputación de Franklin "era más universal que la de Leibnitz o Newton, de Federico el Grande o Voltaire, y su carácter más amado y estimado que ninguno o todos ellos."

Consta igualmente que la reputación "universal" de Franklin no se limitaba a los círculos académicos y científicos, donde se le elogiaba como el autor de "la más bella teoría" sobre la electricidad. El mismo Adams había añadido que su nombre era tan familiar al pueblo como al gobierno, y "a tal grado que apenas si hubo un campesino o ciudadano... que no estuviese familiarizado con él, quien no lo considerase como amigo de la especie humana". Su reputación alcanzaba igualmente, pues, al hombre común, quien asociaba su nombre a cada paso con toda clase de invenciones útiles para el bien y el confort de la humanidad: la estufa que garantizaba mejor calefacción, más limpieza y mayor economía, y que todavía lleva su nombre; las lámparas que perfeccionó para el alumbrado público; las gafas bifocales ; la compañía de bomberos ; el pararrayos; y hasta la mecedora, la que tanta satisfacción da a quien, puestas las buenas gafas, está sentado leyendo El camino de la fortuna junto a la buen estufa de una casita bien protegida de los rayos por el aparato que dasafiaba a los duendes de la tempestad.

15. Bernstein, Origins of Inter-American interest, p. 56. 
La mecedora, y quizá otras invenciones también, bien pudiera haber sido producto de la idolatría desbordante del agradecido pueblo americano. Sea eso como fuere, no había nada legendario, empero, en aquel aparato que fue fruto del célebre experimento en que el práctico e ingenioso Franklin se atrevió a confrontar una de las incógnitas de su tiempo con una cometa, una cuerda y una llave. La fama y la utilidad de aquel pararrayos - sobre el cual Franklin dio un informe ante la Royal Society of London allá por los años 1771-1772- alcanzó a despertar, ya en 1787, la atención de Carlos Cabrer, director de los ingenieros de la lejana ciudad de Buenos Aires, quien recomendó en aquel año que se aprovechara de la invención del gran Franklin para la protección de los edificios y barcos. ${ }^{16}$ Nada más elocuente en este sentido, sin embargo, que el tributo de Francisco Miranda por aquellos mismos años. Fue entre noviembre de 1783 y enero de 1784 que el prócer venezolano, en la ocasión de su bien documentada gira por los Estados Unidos, se acercaba a Philadelphia en barco por el Delaware, admirándose de unos "caballos de frisa" que los americanos habían colocado en el río para obstaculizar el paso de la marina británica. Aquellos "caballos de frisa" le solicitaron al recién llegado Miranda este homenaje espontáneo y revelador:

...una de las más sólidas, y felizes invenciones que pudo producirse en fortificaciones de esta especie ...por quanto no sería el sublime y general Ingenio del Docto Frankling que produjese esta singular invención! el nuevo Sistema de Chimineas en que con una tercera parte de Leña, o carbon de la que comunmente se gasta, se consigue dar mas calór al quarto ó pieza que se intenta Calentar... el Javon famoso para afeitarse que se vende en Boston con el nombre suio - - los conductores para preservación de los Rayos \&. ... con otro sin numero de invenciones, y descubiertos menores, que aunque no tan brillantes como las de las Leyes de la electricidad, y otras de este jaez, son mucho mas utiles al genero humano, han sido productos igualmente de este grande amigo de la Sociedad... 17

16 V. Guillermo Furlong, Artesanos argentinos durante la dominación bispánica. Buenos Aires, 1946, pp. 423-424.

17 Arcbivo del General Miranda. Caracas: Editorial Sur-América, 1929. I, pp. $219-220$. 
Franklin murió el 17 de abril de 1790. La noticia derramó una tristeza casi instantánea por todo el mundo occidental. Si en Francia la Asamblea Nacional guardó luto por él durante tres días y "lloraron muchas bellas francesas", en la distante ciudad porteña de Buenos Aires y en la Córdoba interior de la pampa argentina se sintió el mismo dolor al saber de la muerte de aquel "grande amigo de la Sociedad", hecho comprobado por una carta fechada el 17 de julio de 1790 en que el fraile dominicano Vicente Miró comunicó al fraile Cipriano Negrete de Córdoba que, al preguntar a tres hombres por qué iban de luto por una calle porteña, supo que eran de Boston y que les dolía la noticia de "la muerte de Mr. Benjamín Franklin".18

18 Del Arcbivo del Convento de Córdoba. Citado por Furlong, "The influence of Benjamin Franklin in the River Plate area before 1810", p. 263. Franklin, el físico, siguió vivo en la memoria del siglo pasado dedicado al Ptogreso. Ramón Vélez Herrera (1809-1886) le compuso una oda, "A Franklin, inventor del pararrayos", al estilo Quintana-Olmedo, que lleva de lema las palabras de Turgot y que mereció un puesto en La poesía lirica en Cuba. La Habana: "El Siglo XX", 1928. II, pp. 189-194. Editado por José Manuel Carbonell. Elogiándole primero como uno de los "osados" - Newton, Copérnico, Colón, Descartes, "Fulton sublime":

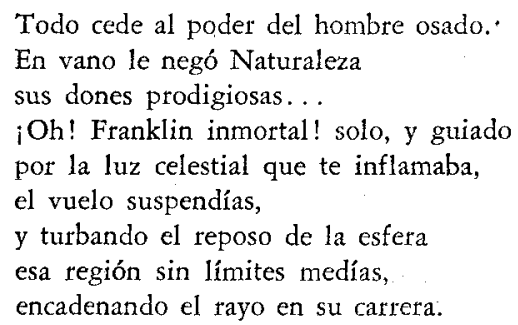

termina con un tributo al Franklin coronado por Minerva, el que venció los "monstruos tiranos":

¿No es eterna la fama que te abona?

¡El mundo un himno a tu alabanza, entona!

¿Quién más digno que tú? ¿No fue tu vida

de la austera virtud sublime ejemplo?

El mismo concepto de Franklin, ilustrado por la medalla estampada con la divisa de Turgot, inspiró otros versos - no del todo felices- por el español A(ntonio) $\mathbf{P}($ irala ) :

$\mathrm{Y}$ el cetro que un poder torpe, inclemente,

A tu querida patria avasallaba, 
El Revolucionario Integral

“...y el cetro a los tiranos".

La inspirada divisa formulada por el Barón Turgot de Francia: "Eripuit coelo fulmen sceptrumque tyrannis" había elevado a Franklin a la categoría de los héroes épicos. Esta divisa embelleció la medalla de nuestro comisario que se vendía en todas partes al llegar Franklin a París en diciembre de 1776. Las dos facetas de su imagen venerada, tan dramáticamente resaltadas en la divisa, repitiéronse en la memoria $\mathrm{y}$ en las Memorias de todos los que le conocieron, como en el caso de Madame Campan que le caracterizó como quien "reunía a la fama de ser uno de los físicos más hábiles, las virtudes patrióticas que le habían hecho abrazar el papel de apóstol de la libertad".

Muchos eran los "apóstoles" que habían contribuido a la realización del "gran sueño" que para Europa representaba el joven país de entonces. Wáshington había capitaneado las harapientas y mal organizadas tropas, encaminándolas a la victoria final. Jéfferson había redactado la "Declaración de Independencia", piedra angular de nuestra naciente literatura nacional. Y había tantos otros - de quienes la historia habría de guardar perennemente fresca la memoria- Patrick Henry, Thomas Paine, John Adams, James Hamilton, que se habían hecho individual y colectivamente inmortales, en la tribuna o en el campo de batalla, por la espada o por la pluma, dentro

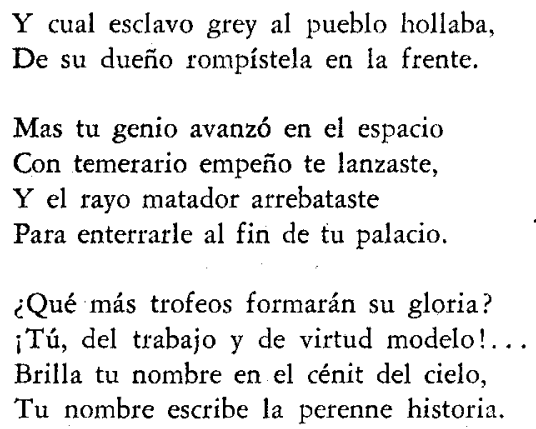

Revista bistórica (Madrid), I (1851), pp. 295-296. 
y fuera del país. Pero por encima de todos elevábase el espíritu del venerable anciano que por casi medio siglo había asistido a todas las asambleas regionales y continentales llamadas a resolver los mil problemas confrontando al pueblo cuando aún era una colonia inglesa. Por ende, una vez firmada la solemne "Declaración" el 4 de julio de 1776, documento en cuya composición Franklin había hecho un papel decisivo, era de esperarse que el Congreso se valiera de él como el compatriota más conocido y estimado en Europa para buscar el apoyo de Francia y otros países continentales, especialmente Holanda y España. En 1785 volvió a su tierra por última vez, después de haber sido el delegado de una y de todas las colonias por más de 25 años de su vida. Medio leyenda ya, la mera presencia del querido y respetado ochentón sirvió para templar las pasiones de los demás, para que de la Asamblea Constituyente de 1787 se levantara la nación unida y fuerte. iCuánto más sentido y valor histórico emanan de palabras como éstas al saber que fueron escritas por quien participó en la redacción de cuatro documentos fundamentales de nuestra gestación nacional: la "Declaración de Independencia", el "Tratado de Alianza con Francia", el "Tratado de Paz con Inglaterra", y la "Constitución de los Estados Unidos de América":

Dios permita que no sólo el amor a la libertad, sino también una plena comprensión de los derechos del hombre puedan extenderse a todas las naciones de la tierra a fin de que el filósofo pueda sentar pie en cualquier parte de su superficie y decir: "Esta es mi Patria".

Tal, en breve, fue el papel del político y diplomático Franklin, el prócer que arrebató "el cetro a los tiranos". La novedad de su persona humilde y democrática "electrizó la viveza natural de las señoras francesas" y el valer y la fuerza de sus argumentos y de su carácter influyeron poderosamente en la política europea de la época. Esto en gran medida fue la consecuencia inevitable de la presencia de su propia persona familiar y querida en todos los círculos diplomáticos. $\mathrm{E}$ inevitable también, no cabe duda, un conocimiento ampliamente generalizado de sus escritos políticos, especialmente en In- 
glaterra, donde no había barrera lingüística, y en Francia, donde su obra fue traducida cuanto antes al francés. Pero de ahí a decir hasta qué punto sus ideas tuviexon resonancia allá de donde en gran parte nacieron como herencia de la ideología revolucionaria americana, no es cosa fácil de determinar con toda precisión. Y mucho menos fácil resulta intentar verificar la boga y la influencia de sus ideas en el mundo español de entonces, donde pocos, por contraste, le habían tratado como el delegado persuasivo de los rebeldes colonos británicos o como el portavoz de nuevos conceptos políticos que, por faltarles en aquel momento traducciones al castellano, apenas llegaban al alcance de los que dominaban el inglés y el francés de tales ediciones que circulasen por la Península y por la América hispana. Además, en la ideología liberal y revolucionaria del mundo hispánico del último tercio del siglo XVIII y de las primeras décadas del siglo XIX van entrañablemente fundidas las distintas corrientes de ideas que en su conjunto eran la base de la Ilustración y del liberalismo político que fructificaron en el ejemplo de Francia y en el movimiento independista de las Américas. A menos que el propio autor - las mismas circunstancias precisen una fuente específica para tal o cual concepto del brillante prisma ideológico de aquellos tiempos, resulta tarea ingrata y estéril intentar diferenciar aún aquellas ideas que fueran de indiscutible origen americano, a no decir nada de intentar poner en relieve la figura y la obra de Franklin como prócer y forjador de ideas que contribuyeron a establecer el país sobre sólidas bases filosóficas e intelectuales.

¿Cómo negar, por ejemplo, que el espíritu de Franklin no conmoviera a Tiradentes, aquel joven mártir de la "Inconfidência Mineira", que en el último tercio del siglo XvirI andaba por todo el Estado proclamando orgullosamente que "o Pais de Minas Gerais era o melhor do Mundo" y debía ser "uma república livre e florescente como a dos americanos ingleses?" Además, sabemos que llevaba consigo un libro escrito en francés y publicado en Suiza en 1778 que contenía la "Declaración de Independencia" y otros actos, decretos y leyes que resumían la filosofía política americana elaborada 
por Franklin, Jéfferson, y otros contemporáneos suyos. ${ }^{19}$ De igual manera, es decir, en francés y en inglés, e inmiscuido en el cuerpo de documentos constitucionales, el mensaje de Franklin captó la imaginación de los liberales emancipadores hispánicos de aquellos tiempos. Fuera de contados fragmentos de algunos tratados científicos, no sabemos de ningún escrito suyo en traducción española hasta la publicación de su Autobiografía en 1798 y de los consejos del Buen Ricardo en 1825. $Y$ no hubo nada esencial de Franklin en portugués hasta 1856.

Franklin tuvo escasos contactos personales con gente responsable de países de habla española y portuguesa. Conoció, empero, a algunos en quienes, indudablemente, dejó una im-presión imborrable. Hasta qué punto éstos fueron receptivos a sus ideas y en qué medida transmitieron tales ideas a sus contemporáneos, ha de quedarse mayormente en el reino de la especulación. Además, esos contactos siempre tuvieron lugar o en los Estados Unidos o en países al norte de los Pirineos. Franklin nunca puso pie en otras tierras americanas, ni parece haber entrado jamás en España.

El primer contacto que tuvo Franklin con un alto personaje político del mundo español fue con el Conde de Aranda, quien estuvo de embajador en Francia entre 1773-1784. Franklin le buscó a principios de 1777, poco después de llegar a París como embajador nuestro, comisionado para solicitar la ayuda moral y financiera de varios países europeos. El Congreso había proyectado aun nombrarle ministro plenipotenciario en España. Pero Franklin se quedó en París, y fue allí donde inició las conversaciones con el "americanista liberal... de gran influencia en la Corte española", cuyo objeto iba a realizarse luego en Madrid mediante los oficios de John Jay. El nombre de Aranda aparece repetidas veces en la correspondencia que hubo entre Jay y Franklin. No sabemos, empero, cuántas veces se trataron directamente, trato que no pudo haber sido enteramente libre e íntimo en vista de que "Franklin hablaba el francés con dificultad, y Aranda no sabía el inglés". Con todo, parece que, a pesar de la barrera lingüística, "los dos

19 V. mi estudio A literatura norteamericana no Brasil. México, 1950, pp. 3-4. 
simpatizaron y entablaron una amistad que duró el resto de sus vidas".20

Con esa misma España-liberal, Franklin tuvo otro contacto personal que años más tarde dio resultados históricos debidos, en gran parte, indudablemente, a las observaciones hechas y las cosas aprendidas por el Padre Antonio Ruiz de Padrón durante su largo viaje por el país. El momento culminante de aquel viaje debió ser su visita a Philadelphia, donde, en la misma casa de Franklin, conoció también a otros distinguidos intelectuales americanos. Al plantearse la cuestión del futuro de la Inquisición, el Padre Antonio participó decisivamente en los debates que se sostuvieron en las Cortes de Cádiz desde el 22 de abril de 1812 hasta el 13 de febrero de 1813, cuando se decretó abolida una institución que, en las palabras del padre, "era enteramente inútil en la Iglesia de Dios, en contradicción con la Constitución y en oposición al espíritu de la Biblia"..21

No sabemos que el Conde Pedro Rodríguez de Campomanes (1723-1802), presidente de la Real Academia de la Historia desde 1764 hasta 1791 - es decir, contemporáneamente con Franklin, que lo era de la American Philosophical Society desde 1769 hasta su muerte en 1790- jamás conociera personalmente a Franklin. Consérvanse, sin embargo, dos cartas en la correspondencia de Franklin que iluminan las relaciones entre los dos en el año de 1784, año en que el uno y el otro se propusieron como miembros correspondientes de sus respectivas sociedades. Las dos merecen ser citadas aquí casi in toto tanto por el contenido como por el tono de ambos. La de Franklin, fechada en Passy el 5 de junio, reza así:

I have received much Instruction and Pleasure in reading your excellent Writings... You are engaged in a great Work,

20 V. José de Onís, "Benjamín Franklin, ciudadano de América", IPNA, 29 (1955), pp. 25-27.

21 V. Discusión del proyecto de decreto sobre el Tribunal de la Inquisición. Cádiz, 1813, pp. 219.232. Citado por J. R. Spell, Rousseau in the Spanisb World before 1833. Austin: The University of Texas Press, 1938, p. 194. Interesa notar que la Nortb American Review publicó largas citas del discurso del Padre Antonio. V. E. F. Helman, "Early interest in Spanish in New England (1815-1835)", Hispasia, XXIX (1946), pp. 339-351. 
reforming the ancient Habitudes, removing the Prejudices, and promoting the Industry of your Nation. You have in the Spanish People good Stuff to work upon, and by a steady Perseverance you will obtain perhaps a Success beyond your Expectation; for it is incredible the quantity of Good that may be done in a Country by a single Man, who will make a Business of it, and not suffer himself to be diverted from that Purpose by different Avocations, Studies, or Amusements.

There are two Opinions prevalent in Europe, which have mischievous Effects in diminishing national Felicity; the one, that useful Labour is dishonourable; the other, that Families may be perpetuated with Estates. In America we have neither of these Prejudices, which is a great Advantage to us. You will see our Ideas respecting the first, in a little Piece I send you, called Information to those who would remove to America. The second is mathematically demonstrable to be an Impossibility under the present Rules of Law and Religion... in only nine Generations the present Proprietor's Part in the then Possessor of the Estate will be but a 512th, supposing the Fidelity of all the succeeding Wives equally certain with that of those now existing: Too small a Portion, methinks, to be anxious about, so as to oppose a legal Liberty of breaking Entails and dividing Estates, which wrould contribute so much to the Prosperity of the Country...22

A la cual respondió Campomanes; en carta fechada el 26 de julio:

I have received, by the hands of my friend $\mathrm{Mr}$. Carmichael, your estimable letter of the 5th of June, the collection of your miscellaneous writings, and the piece entitled, Information to those who would remove to America. All these writings exhibit proofs of their having proceeded from a statesman, endowed with foresight, and vigilant for the best interests of his country, ... (and) for the general happiness of mankind...

The frankness, with which you dissuade people in Europe from emigrating inconsiderately to America, is a proof of your general philanthropy, and of a candor peculiar to a good man, true philosopher, and genuine patriot. You extend this same benevolence to Spain, in your remarks respecting the honour that is due to labour, and against the entailment of estates. The former is now confirmed among us by a recent law, a copy of 22 The Writings of Benjamin Franklin. ivew York: Macmillan, 1907, IX. pp. 221-223. 
which I send herewith, declaring the honourable light in which every description of artisans should be regarded. Labourers were always honoured and favoured by our laws. As to what regards entailments, I refer you to what I wrote in the year I have, at the end of my treatise upon Mortmain, in which I think I have demonstrated, that another regulation ought to precede this in the progress of legislation. I add also, that there is some diversity of circumstances between a monarchical and democratical constitution in this respect.

I should have great pleasure in extending these reflections, if time would permit, although your penetration and sagacity would render them unnecessary. The honour conferred upon me by The American Philosophical Society, in electing me a member on the 16th of January, lays me under the pleasing obligation of expressing my gratitude through you, the worthy President of the Society. Desirous of reciprocating in some manner this act of courtesy, I proposed you as an honourary member of the Royal Academy of History, of which I am President. The proposal was responded to by universal acclamation; the Academy feeling in the highest degree honoured by having on its list the name of a man so eminent in the world of letters, and so distinguished for the part he has acted in a Revolution, the most memorable in the history of modern times. ${ }^{23}$

Con lo cual se comprende que aquel ilustre economista y político liberal del reinado de Carlos III no pudo menos de haber sido devoto lector y admirador de la literatura revolucionaria nuestra de entonces, cambiando ideas con correligionarios como el Conde de Aranda y el Padre Ruiz de Padrón y convenciendo a otros que "convenía a España a entrar en relaciones permanentes y democráticas con los Estados Unidos". ${ }^{4}$

Tampoco consta que Franklin entablara amistad personal con hispanoamericanos conocidos en Europa o en los Estados Unidos, o que estuviera en contacto con muchos que vinieron tempranamente a nuestras playas, atraídos por el éxito de nuestro movimiento separatista y por el ejemplo político inmortalizado en la histórica "Declaración". Ya comentamos

23 Ibid., p. 223. No conozco el original en español.

24 V. W. C. Ford, The United States and Spain in 1790, p. 40. Citado por Bernstein, Origins of Inter-American interest, p. 55. A pesar de que nuestras relaciones con Portugal no eran nada cordiales por aquel entonces, ya antes de 1800 la American Philosophical Society había nombrado miembro correspondiente del país al ministro Conde de Caylus, Cipriano Rivera Freire. 
sobre la admiración que sentía el dinámico protoprócer Francisco Miranda por el "sublime y general Ingenio" del eminente físico Franklin, pero no hay prueba irrefutable de que jamás llegara a estrechar la mano del que lanzó la histórica cometa. Desde luego, no pudo haber sido cuando su gira por el país durante el período 1783-1784. Franklin estuvo en Europa por aquel entonces. El nombre de Franklin no figura en las largas listas de hombres y mujeres, representativos de los más diversos y más distinguidos elementos — tanto de Charleston, Philadelphia, New York y Boston, como de Londres y París y otras partes-conocidos en los viajes que tan meticulosamente apuntaba el venezolano en sus diarios. $Y$, sin embargo, hay quienes afirman, o por lo menos insinúan, que Franklin y Miranda se habían tratado de amigos. Cuando, en 1793, Joel Barlow defendió al General Miranda ante el Tribunal Militar de la República Francesa, confesó no conocer él personalmente al prócer venezolano. Apresuróse, empero, a afirmar que todos sus compatriotas intercederían por él. Al hacer mención específica de Wáshington y Franklin, dio a entender que tanto Franklin como Wáshington -y a éste sabemos bien que le conoció Miranda en más de una ocasiónpudo hablar en su favor a base del trato directo: "Mais si Washington ou Franklin étaient ici, ils vous diraient que l' homme que vous allez juger a bien mérité de l'humanité pendant plus de vingt ans, non seulement par ses vertus, mais par les sacrifices qu'il n'a cessé de lui faire." ${ }_{25} \mathrm{Y}$ ante el mismo Tribunal, Chauveau Lagarde afirmó que entre otros Miranda contaba a Franklin, Wáshington, Hamilton, Paine, Adams, Livingston, "pour amis les hommes les plus recommandables par leurs vertus, leur génie et leurs travaux en faveur de la liberté..." ${ }^{26}$ De todos modos resulta obvio que a Miranda no le faltaba tratar directamente a quien ya tenía en alta estima antes de su arribo al país donde hasta una "mosa y no mal paresida" mesonera de Windsor, Connecticutt, le respondió sin dilación que "en su opinión, Franklin era superior a Aristedes..." ${ }^{27}$ En Boston, sí, en esa misma gira, su contacto fue

25 Arcbivo del General Miranda. XII, p. 158.

26 Ibid., p. 249.

27 Archivo del General Miranda. I, p. 277. 
más íntimo. En su visita a los cementerios le gustaba leer las inscripciones sepulcrales, y especialmente la que el doctor Franklin había escrito para la tumba de sus padres, la cual "merece ser transcripta... por su manera y sensillez..." $\mathrm{Y}$ la transcribió entera, en el original. ${ }^{28}$

El Archivo confirma que Miranda debió haber sido reconocido por sus contemporáneos como gran admirador y asiduo lector de Franklin. Una carta de Madame D'Eon, fechada en Londres el 23 de enero de 1792, indica muy a las claras que Miranda compartía esa admiración con conocidos de Franklin y que animaba a los dueños de su obra que la permitiese circular en manos ajenas. Madame le pidió perdón, en francés, por haber guardado tanto tiempo la Vida, de Franklin, y las Ruinas, de Volney, propiedad, según parece, de Piggott, amigo de Miranda, añadiendo que había tomado "des notes sur la vie \& la mémoires de Franklin avec qui elle vivait souvent tant à Londres qu'à París. . . (sic)".$^{20}$ Poco después, como preso en La Force, París, esperando ser procesado por el Tribunal Militar, Miranda tuvo amplia oportunidad de discutir estrategia militar e ideas y sistemas políticos con los liberales franceses encarcelados con él. En tales debates debió figurar prominentemente el nombre de Franklin, cuya obra y ejemplo el prócer venezolano habría defendido con notable ardor porque, al suicidarse el "desgraciado amigo" Achille du Châtelet en marzo de 1794, quiso que Miranda heredara, entre otros efectos suyos, sus ediciones de la obra de Franklin, Bossuet, Hobbes, et al. ${ }^{30}$ Es fácil concluir, pues, que el americano Miranda leyera con suma satisfacción la siguiente sugerencia hecha en una carta fechada en Londres el 19 de noviembre de 1792 en que A. Jardine comenta el papel de Francia y particularmente el de los Estados Unidos en apresurar la caída de las monarquías europeas: "We Europeans ought to invite more of these wise Americans among us. You see Franklin,

28 Ibid., pp. 320-321.

29 Arcbivo del General Miranda. VI, pp. 160-161.

$30 \mathrm{~V}$. William Spence Robertson, The Life of Miranda. Chapel Hill: The University of North Carolina Press, 1929. I, pp. 145-147. 
Paine, Barlow, have scattered more truths of importance among us than all Europe could do for themselves." 31

Miranda se ofrece como un caso ejemplar del americano en estrecho contacto con los personajes y las ideas de la Europa liberal de su tiempo y, a través de éstos, con aquéllos también que dieron vida a la patria de Wáshington y Franklin. ¿Se puede afirmar que más o menos de manera igual el mensaje político y cívico de Franklin cautivara la conciencia de aquellos jóvenes que en distintas partes de la América misma fundaron sociedades y círculos literarios, de encubiertos fines patrióticos, con el objeto de estudiar las novísimas teorías políticas y determinar los medios con que iniciar un movimiento separatista igual al de las colonias británicas? Ya señalamos que nuestra literatura política llegaba allá en inglés y en francés y que en ella iba representado el pensamiento de Franklin. Pero sabemos, además, que ya a fines del siglo xvirI y a principios del XIX, también circulaban ejemplares de la edición de Londres de 1793 de Works of the Late Doctor Benjamin Franklin y del célebre tratado Rules to convert a small state into a great power, presented to a British Minister in 1764 , éstos en Venezuela, y en Argentina otros tantos ejemplares de la primera en la edición de Charleston de $1798 .^{32}$ Muchos de los jóvenes fundadores de aquellas sociedades patriótico-literarias habían viajado y estudiado en el extranjero. Es posible, pues, que a ellos se deba la introducción y difusión de la mayoría de obras extranjeras de tal índole.

Existen catálogos, o inventarios por lo menos, de algunas de las bibliotecas de aquellos fundadores. Una de las más ricas, y de más interés para este estudio, fue la del neogranadino Antonio Nariño (1765-1823), uno de los pocos que en 1793 conspiraban ya de verdad contra la Metrópoli. Desde su primera infancia, Nariño se entusiasmó por la historia de la emancipación de los Estados Unidos, y en su biblioteca dominaban los libros sobre derecho público, matemáticas y física. Se ha dicho que fue de su amor a esta última ciencia que

31 Archivo del General Miranda. VI, p. 218.

32 V. Furlong, "The influence of Benjamin Franklin in the River Plate area before $1810^{\prime \prime}$. 
provenía su conocida veneración por Franklin. ${ }^{33}$ Es evidente, empero, que no fue atraído sólo por el Franklin científico. Cuando allá por 1793, el neogranadino proyectó establecer un círculo patriótico-literario, quería consagrarlo a "la Libertad, la Razón, y la Filosofía, al Divino Platón, y a Franklin". Pero por haber impreso clandestinamente los Derechos del hombre, de Paine, fue perseguido y desterrado, y el proyecto naufragó. Al registrar su casa, encontráronse un cuadro de Franklin en un lugar de honor en la biblioteca, y "los diseños o dibujos con que se proponía adornar la sala destinada a la asociación". Eran éstos "alegorías con inscripciones copiadas de la tumba de Franklin y de las obras de Rousseau".34

El caso de Nariño es doblemente interesante por que, sin poder negar el impacto directo de Franklin, se ve muy a las claras que tal impacto vino bien acompañado de otros de notable parecido ideológico, como los de Paine y Rousseau. Por eso, en el momento de querer precisar el significado de tal o cual impacto, se mete uno en un terreno más que discutible. $\mathrm{El}$ intento resulta especialmente complicado cuando de Paine y Franklin se trata. ¿Cómo, por ejemplo, analizar el caso del esporádico escritor peruano y político fogoso, Francisco $\mathrm{Xa}$ vier de Luna Pizarro, primer presidente del Congreso Constituyente de 1822, en cuya biblioteca figuraban al lado de una Miscelánea de Franklin el Federalista de Hamilton y Los derechos del hombre de Paine. ${ }^{35}$ Sin documentar una afirmación quizá algún tanto categórica, explícase el dilema en esta forma:

Indirectamente a través de Paine, hubo de llegar también la acción ejemplar de Franklin en cuanto a la remoción de antiguos prejuicios y eliminación del vasallaje colonial que allí se condenaba, y tal actitud fomentó el espíritu revolucionario de la América hispana, con una fuerza expansiva indiscutible. Al conside-

33 V. Gustavo Otero Muñoz, Semblanzas colombianas. Bogotá: Editorial ABC, 1938, p. 140 .

34 Ibid., pp. 139-140. C. L. Chandler, Inter-American Acquaintances. 2 ed. University of Sewanee Press, 1917 , p. 16, dice que había entre sus libros un sumario de la revolución americana y una compilación de la ley básica del país, ambos en francés.

35 V. F. Schwab, "El inventario de la biblioteca de Francisco Javier de Luna Pizarro", Fénix (Lima), 7 (1950). Citado por Núñez, "Franklin en América hispana", p. 10 . 
rarse, en América, y en Europa, sobre todo, el folleto de Paine como escrito por Franklin, se estaba afirmando la acción ideológica de éste y reconociéndose con certeza, por lo menos, el carácter de su verdadera ideología, aun en los escritos de su discípulo y protegido." 36

Explícita e implícitamente se ha asociado el nombre de Franklin con el de otros muchos próceres de aquellos tiempos - tanto de los años turbulentos de incipiente vida nacional como de fines de la época colonial-reconocidos casi todos como discípulos, o admiradores, por lo menos, de Rousseau. De tanto mayor trascendencia resulta el señalado lazo entre Franklin y Lizardi al afirmar Luis Alberto Sánchez que "El Pensador Mexicano... representa el esfuerzo más eficaz del periodismo al servicio de la Causa emancipadora". La deuda de Lizardi para con Rousseau es notoria..$^{37}$ Pero nadie menos que Jéfferson entra allí también: "Bajo la no lejana influencia jeffersoniana, se advierte que fructifica allí el ejemplo de Franklin y su memorable 'Gaceta de Boston' (sic)".38 Y si por un lado el cauteloso Menéndez y Pelayo recuerda a Franklin, leyendo los diálogos de Jacinto Chano y Ramón Contreras de los poemas gauchescos del bardo patriótico Bartolomé Hidalgo- "describiendo el uno lo que vio en las fiestas de mayo en Buenos Aires, el año 1822, y dando el otro sanos consejos políticos, con sentido común análogo al del buen hombre Ricardo", ${ }^{39}$ por el otro, tanto é ${ }^{40}$ como Spell ${ }^{41}$ insinúan por lo menos que el espíritu y la obra de Quintana, el poeta patrió-

36 Núñez, "Franklin en América hispana", p. 12. Véase el ejemplo concreto. que nos of rece el mismo Núñez, de la "trascendente acción ideológica de Paine -e indirectamente de la de Franklin- en la edición limeña de 1821 de unas Reflexiones politicas escritas bajo el título de instinto común por un escritor que se ocultaba con el seudónimo de "Anselmo Natiece, indígena del Perú". Estas "Reflexiones", no eran sino "la versión peruana de El sentido común, ... la que más acusaba la influencia de Franklin".

37 V. Spell, op. cit., pp. 246-247.

38 Nueva bistoria de la literatura americana. Asunción: Editorial Guarania, 1950, p. 152. Sánchez quería referirse a la Pennsylvania Gazette (1727-1765).

39 Historia de la poesía hispanoamericana. Madrid: V. Suárez, 1911-1913. II. p, 468 .

40 Estudios de critica literaria. V, p. 335.

41 Op. cit., p. 175. 
tico por antonomasia de todo el mundo español, denuncian un fuerte paralelo con los de Franklin.

Aun descontando tales insinuaciones y conjeturas algo arriesgadas, es innegable que la ideología política de Franklin ejerció una decidida influencia, directa e indirecta, en la gestación y maduración de la conciencia liberal del mundo hispano. Pero una vez realizado el gesto independista, e iniciada la vida nacional con un complejo de ideas o ideales nuevos y a menudo contradictorios, en que el límpido liberalismo de la época de los próceres de la emancipación caía aceleradamente en el limbo ideológico, era de esperarse que más y más se asociara la filosofía política de Franklin con un momento ya definitivamente pasado de la vida norteamericana. El concepto de una América de prístinas virtudes democráticas y liberales plasmóse plenamente en la conciencia hispánica cuando los malos frutos (el General Walker, filibusteros, la desmembración de México) de la doctrina de Monroe y la política de "Manifest Destiny" parecían denunciar que esa América perteneció irrevocablemente ya a la historia. Por ende, en los momentos de crisis entre un país hispano y los Estados Unidos, se empezó a distinguir entre el poderoso país de aparentes tendencias imperialistas y el "país de Washington y Franklin". Así fue, por ejemplo, en el caso del federalista colombiano, el General Pedro A. Herrán (1800-1872), gran admirador del sistema político americano y sin duda también de los próceres cuyo mensaje, según el centralista José Joaquín Borda, ya (1860) no tenían validez allá: "Yo deseo que volvamos al centralismo, al gobierno unitario y fuerte, único que puede salvar y contener las ramas de la fogosa raza latina ... Los retratos de Wáshington, de Madison y Jéfferson, cuyos nombres invoca usted [Tanco] en su folleto, quedan mejor colocados en el Capitolio de la Unión americana". ${ }^{2}$ Tres veces Herrán fue nombrado a representar a su país ante los Estados Unidos. La segunda vez fue entre 1855 y 1859, "en el momento de los graves asuntos [reconocimiento del gobierno implantado en Guatemala por Walker y el sangriento motín de Panamá] que

42 Eduardo Posada y Pedro M. Ibáñez, Vida de Herrán. Bogotá: Imprenta Nacional, 1903, p. 305. 
hicieron indispensable su presencia otra vez en la tierra de Franklin". Y sin embargo, si habíamos de creer a los liberales, el General Herrán no aprendió nada del auténtico sentido democrático, a pesar de tantos años de residencia en los Estados Unidos. Dicha acusación la hizo el liberal Felipe Pérez al hablar de la elección de Herrán como gobernador de Antioquia: "El partido liberal, por su parte, apoyó hasta cierto punto esta candidatura, pues pensó, aunque equivocadamente, que nuestro ex-Presidente había adquirido algunas ideas de progreso y de bien entendida democracia con su larga residencia en el país de Wáshington y Franklin". ${ }^{43} \mathrm{El}$ concepto del prócer político se juntó con el del "Leonardo americano" para entrar ambos en la historia. ${ }^{44}$

El Platón Casero

\author{
"la misma encarnación de la \\ cordura y del sentido claro."
}

MATTHEW ARNOLD.

El tercer concepto -el del severo moralista, del buen ciudadano, del benefactor público - personificado en los epítetos: el "Platón casero" y el "Buen Ricardo", surge en el

43 Ibid., pp. 292-293. Por contraste, el Dr. Francia del Paraguay, ofreció un retrato de Franklin a los delegados argentinos, elogiándolo como el primer demóciata del mundo y como ciudadano modelo digno de ser imitado. V. Chandler, op. cit., p. 44 .

44 Al menos un artículo del "prócer político" gozó posteriormente de una contemporaneidad efectiva. Véase, por ejemplo, el incidente-relatado por Rafael Heliodoro Valle-que se relaciona directamente con la libertad de la expresión de Honduras en cierta ocasión cuando el poeta Juan Ramón Molina (1875-1908) era director del Diario de Honduras bajo el régimen del dictador Terencio Sierra. Incapacitado para escribir el editorial, Molina "recurrió a un artículo de Franklin, que se titula 'El hacha que afila', en que Franklin aconseja que cuando un tirano aparece en el horizonte es conveniente afilar el hacha. La edición del periódico apareció con el artículo frankliniano, y el dictador, enfurecido, llamó al periodista increpándole por su audacia al querer poner en movimiento el hacha libertadora". Desgraciadamente la cosa terminó mal para Molina. No queriendo creer que Franklin había escrito dicho artículo, el dictador humilló al poeta, "obligándole a que con una carretilla de manos trabajase acarreando piedra y tierra en la apertura de una carretera". "Dimensión de Franklin", IPNA, 29 (1955), p. 29. Y quizá no sea nota del todo intruso recordar que Ricardo Molina encabezó su artículo sobre 
momento en que las jóvenes naciones americanas aspiran a crear una nueva conciencia cívica de parte del gran pueblo que por más de tres siglos había quedado más o menos al margen del proceso evolutivo de la sociedad colonial. Los forjadores de las nuevas patrias formularon divisas y lemas: "gobernar es poblar", "gobernar es educar", y enaltecieron la vida de aquellos hombres del pasado y del presente que más habían contribuido para la mejora del destino del "Gran Soberano". En la poderosa nación hermana del Norte, la que les había enseñado el camino de ser pueblo democrático y libre, muchos descubrieron modelos del tipo ciudadano que mejor encuadrara en la nueva sociedad que anhelaban establecer y que más garantías pareciera dar a que entre ellos también se realizara plenamente el "gran sueño" americano. De entre todos los enaltecidos fundadores de la patria norteña - los Wáshington, Jéfferson, Hamilton, Adams, Franklin- había sólo uno en que parecieran ser resumidas todas las cualidades y características que se identificaron ya en aquel entonces como las del "yankee," el reconocido tipo nacional. En el autodidacta Franklin, de humilde ascendencia y de espíritu democrático ejemplar, quien quiso entrar en la historia - según el epitafio que él mismo preparó para su tumba en Philadelphia- como un humilde impresor cuya obra nunca se iba a perder porque, como él esperaba, "habría de aparecer una vez más en una nueva y más elegante edición revisada y corregida por el Autor" Supremo, en aquel hombre sencillo, práctico, trabajador e ingenioso de altas virtudes morales y cívicas, el siglo XIX creyó ver el auténtico prototipo americano.

$\mathrm{Y}$ efectivamente, de una manera en que el humilde impresor jamás lo pensara, desde fines del siglo XVIII nuevas ediciones de su Autobiografía y de su Almanaque siguiéronse en traducciones españolas y portuguesas, y los dichos y máximas del pobre y buen Ricardo repitiéronse en la prensa hispánica de generación en generación. Y más aún. A menudo tales ediciones fueron revisadas y adaptadas de modo que su

el espinoso asunto de "Gibraitar" con estas palabras de Franklin: "El mismo derecho tienen los ingleses para conservar a Gibraltar, que tendrían los españoles para exigir que se les entregase a Plymouth". Crónica de ambos mundos (Madrid). I (19 agosto 1860), pp. 181-183. 
mensaje fuese tanto más útil para el público lector a que iba destinado - e iba acompañado a veces de páginas originales de una más obvia utilidad inmediata e interesada. En edición de Caracas, de 1858 por ejemplo, La ciencia del Buen Ricardo fue seguido de un artículo por José María Samper, intitulado "Pensamientos sobre moral, política, literatura, religión y costumbres". Y en la edición chilena de 1885, la Caja de Ahorros de Santiago aprovechó un "Apéndice" de tres páginas para indicar al obrero chileno poner en práctica las buenas lecciones aprendidas en El camino de la fortuna o sea vida y obras de Benjamín Franklin.45 $\mathrm{Y}$ en un mismo año, el de 1897, Genaro Lugo se dirigió "A los artesanos de Centro-América" en el prólogo de Ofrenda a los artesanos. Benjamín Franklin. $E l$ arte de hacerse rico (Managua), mientras que en Lima el Partido Demócrata incluyó en la segunda parte de su Manual del demócrata peruano una serie de opúsculos sacados de su Libro del hombre de bien. Hay noticia, además, de que quizá con el loable intento de alcanzar el mayor círculo posible de

45 Sirviéndose, como lema, del consejo de Franklin de que no disipen ni el tiempo ni el dinero, la Caja anima a los obreros a que ahorren "todos los días una parte, por pequeña que sea, de su ganancia o de su salario... Esperamos que el ejemplo de Franklin despierte... el deseo de imitarle i que, en consecuencia, la práctica de la economía i del ahorro llegue a hacerse habitual en muchos de ellos... Franklin dice que 'los obreros podrían mejorar su condición i adquirir poco a poco fortuna, si por regla jeneral no tuviesen la mala costumbre de considerar todo aumento en su salario como un motivo para trabajar menos i beber más'. Esta observación de Franklin se funda en su experiencia personal puesto que mediante el trabajo, la honradez i la economía, él pudo elevarse desde el humilde taller de una imprenta hasta las cimas del poder, de la fortuna $i$ de la gloria. Nuestros obreros no llegarán tal vez a esas alturas; pero a lo menos podrán obtener su independencia personal $\mathrm{i}$ asegurar el pan de sus hijos, si inspirándose en el modelo que les presentamos, trabajan con perseverancia $\mathrm{i}$ abandonan el camino que conduce a los sitios en donde se disipa el tiempo y el dinero para tomar todos los domingos el que lleva a la Caja de Ahorros establecida en Santiago para ayudarles a hacer provechosas economías i a evitar los derroches del vicio o de la vanidad". Interesa notar por lo menos que tanto el arreglo de Valdés Vergara, en la segunda edición de 1900, como la nutrida reseña que sobre él escribió Eduardo Lamas para La revista de Cbile (V, 15 octubre 1900, pp. 244-248; 1 noviembre 1900, pp. 268 272) tuvo fruto inmediato en un corto artículo anónimo "Sobre el alcoholismo", publicado en La revista de Cbile (VI, 15 abril 1901, p. 225). El artículo empieza con la anécdota del tratado de paz que firmaron Franklin y Morris con los indios de Carlisle. 
lectores, Enrique Seoane del Perú puso en verso los consejos del Buen Ricardo. ${ }^{46}$ Pero en esto de aprovechar el aspecto económico-moral, digamos, del mensaje de Franklin, los de lengua portuguesa se habrán mostrado aún más utilitarios que sus hermanos de lengua española. Los "Conselhos para fazer fortuna" de Franklin ocupan unas diez páginas de las Verdades económicas ou a riqueza ao alcance de todos impreso en Lisboa en 1876. De aún mayor aplicación directa y limitada fue el folleto intitulado Aforismo doméstico para legítimos constitucionaes, ou ciência do homem Ricardo dando um meio fácil para pagar tributos, impreso en Río, sin fecha, por la Imprenta Nacional, muestra convincente de la veneración casi idolátrica, en que le tenían los cariocas al considerar a Franklin como la persona más indicada para señalarles el camino menos penoso por el cual cumplir con sus obligaciones tributarias. Nada más claro, empero, que la advertencia del editor brasileño de una edición carioca, allá por 1901, de la Ciência do bom homem Ricardo, en la cual se particularizan las ventajas que serán de quien compre este libro de que "...em França consumiram-se em menos de quatro annos quarenta mil exemplares...": "O bom homem Ricardo encanta e persuade, quando nos pinta o homem laborioso, económico e bom, prestando úteis serviços aos seus semelhantes... Possam convencerse os homens, e mórmente os brasileiros, que a felicidade individual, assim como a properidade nacional, sómente lhes pode vir do amor da justiça, dos esforços da indústria, e dos hábitos de trabalho e da econômia."

No faltaba sino que los sanos consejos del Buen Ricardo llegasen al conocimiento de la juventud dentro y fuera de la escuela, lo cual se realizó con la edición bonaerense de 1873, La economía política puesta al alcance de los niños, vertida al castellano "para el uso de las escuelas de la República Arjentina..." Y simultáneamente el Almanaque de Bom Homem Ricardo "foi libro de leitura de escola primária no interior do Brasil, na segunda metade do século XIX". ${ }^{47}$ Desde entonces

46 Según Constantino Carrasco en El correo del Perí correspondiente a diciembre de 1874 .

47 V. mi estudio A literatura norteamericana no Brasil, p. 44, nota 16. 
ha habido varias ediciones destinadas para los jóvenes, o como libro de amena lectura ${ }^{48}$ o como texto escolar (Heath), y pocas son las antologías en que no vayan incluídos algunos trozos o máximas del Buen Ricardo.

Ocurrió, pues, que el nombre del "Platón casero" vino a ser tan conocido y tan querido en el mundo hispánico como en su tierra natal. Tan honda fue esa veneraciôn compartida por todas las clases sociales, y por los maestros y los padres, que ya desde la cuna se quiso garantizar que viviera una vida tan útil y tan ejemplar como la del ciudadano-modelo con cuyo nombre bautizaran al recién nacido. Evidentemente más de un hombre crecido había guardado con parecida emoción el mismo recuerdo nostálgico que expresara Afrânio Peixoto al examinar "com olhos comovidos" un ejemplar de la misma edición del Almanaque do bom homem Ricardo que le había servido de texto escolar en el sertâo de su amada Bahía. ¿No fue el caso, tal vez, de los padres del célebre novelista sertanejo, João Franklin da Silveira Távora (1842-1888), o el, seguramente, de los progenitores del crítico e historiador, Benjamín Franklin Ramiz Galvão (1846-1938) ? Y al establecerse una nueva biblioteca pública, ¿cómo no pensar en quien fundara ya en el primer tercio del siglo pasado (1731) la primera Biblioteca Popular Circulante americana y hacer en el último tercio del siglo XIX lo que los compatriotas de Sarmiento, bautizarla Biblioteca Franklin de San Juan? Homenaje que se repitió de común acuerdo entre los de México y Estados Unidos cuando en 1942 se estableció en la capital azteca la ya renombrada "Benjamin Franklin Library", madre de una familia de bibliotecas americanas que hoy mantienen la "tierra de Franklin" en constante y estrecha relación con el gran pueblo del mundo hispano. Y motivado por el mismo deseo de rendir tributo al abnegado benefactor público de Philadelphia, allá a principios de siglo, un grupo de estudiantes universitarios chilenos, casi todos de familias ricas y de alta sociedad, fundó la Sociedad Franklin con el propósito de establecer

48 V. la edición "Juvenil Ercilla", cuya nota prologal reza así: "Pocas vidas resultarán tan ejemplares para la niñez y para la juventud como la de Benjamín Franklin el creador, por decirlo así, de los Estados Unidos de América". 
escuelas nocturnas para adultos. $\mathrm{Y}$ a esas escuelas que fundaron y mantuvieron con su propio dinero y su trabajo personal dieron el nombre de "Escuela Nocturna Benjamín Franklin".49

Como libro útil y ameno o como texto escolar los sabios consejos del Buen Ricardo contribuyeron mucho a la formación de los prohombres de ayer que mediante bibliotecas y escuelas emprendieron la ardua tarea "de convertir en pueblo el populacho" - de crear Patria. Puede que aún en los días cuando se veneraba a Franklin como el ingenioso "físico" de la Ilustración y como el prócer-modelo del movimiento separatista, hubiera unos que ya vieron en el "filósofo juicioso" el prototipo del futuro ciudadano ejemplar de los pueblos aun por nacer. Se ha citado nada menos que al iluminado maestro de Bolívar como uno de los primeros abanderados de Franklin en la América del Sur.50 Bien pudiera ser que Simón Rodríguez (1771-1854) se sintiera fuertemente atraído por el ejemplo y la palabra de Franklin en torno a la educación popular. Además, es muy probable que llegasen a las manos del inquieto caraqueño algunos escritos del sabio norteamericano que circulaban allí aun antes de su salida en 1797 para Jamaica, Estados Unidos y Londres. ${ }^{51}$ Pero nada cierto se sabe de su visita, y las pocas alusiones al "país de Franklin" que se encuentran posteriormente en sus escritos no son nada halagadoras. Se colige que para él —esto correspondería más bien a sus últimos años- los Estados Unidos eran "más cuerpo que alma" y que el ejemplo de su inmoderada prosperidad material no pudo ser sino perjudicial a los pobres hermanos pueblos del Sur. Nunca cita a Franklin, ni en sus obras donde de manera más enfática y original defiende su ideología educativa profundamente rousseaniana - Rousseau es uno de los poquísimos citados por don Simón- ni en una obra tan rotundamente didáctica como Luces y virtudes sociales (Concepción,

49 V. Alberto Masferrer, Páginas escogidas. San Salvador: Ministerio de Cultura, 1953, pp. 223-226. Y también La Escuela Nocturna "Benjamin Franklin". Santiago: Imprenta "Letras", 1937.

50 V. Núñez, "Franklin en América hispana", p. 16.

01 Tales, por ejemplo, los panfletos Proposals relating to the education of youtb in Pennsylvania (1749) y Idea of the English school (1751). 
1834) en donde salen muy patentes "las máximas de moral práctica y las recomendaciones de buen sentido tan características de Franklin".52 De todos modos el caso del visionario maestro del Libertador ofrécese por lo menos como un paralelo interesante respecto a ideas y sistemas educacionales casi simultáneamente sostenidos en ambas Américas como mejor apropiados para las nuevas sociedades en gestación.

Una vez constituidos estos nuevos pueblos no es nada infrecuente que se compare a sus más ilustres y respetados hijos civiles con el prohombre de Franklin del norte. El dominicano Manuel de Jesús Galván encuentra un fuerte paralelo, tanto físico como espiritual, en su conciudadano Ulises Francisco Espaillat (1823-1878) —uno de los hombres de la Restauración, que había ejercido interinamente las funciones de Presidente de la República en armas y "merecía el unánime respeto de sus compatriotas":

"Espaillat presentaba, fisonómica e intelectualmente, una sorprendente semejanza con Benjamín Franklin. En efecto: si su rostro evocaba la imagen del austero patriota y moralista norteamericano, también encontramos en uno y otro la misma pureza moral, la misma precisión del razonamiento, la misma clarividencia práctica de las cosas, el mismo don del 'buen sentido'."

De otros muchos paralelos con Franklin que se pudieran aducir, de mayor significación - por tratarse de un célebre publicista cuya palabra y cuya persona alcanzaron a ejercer una marcada influencia por todo el mundo hispano- sería el del ilustre prócer puertorriqueño Eugenio María de Hostos (1839-1903). Aunque no haya sino una sola referencia a Franklin en toda su variada y extensa obra de moralista, educador y sociólogo, esa referencia basta para confirmar que el mensaje y el ejemplo del "padre de la patria americana" no pasaban inadvertidos al autor del Tratado de moral, la Moral social y demás obras de parecida índole. Se la encuentra justamente en el Libro Cuatro, "Moral social objetiva", de su

52 V. Núñez, "Franklin en América hispana", p. 16.

53 V. Max Henriquez Ureña, Panorama bistórico de la literatura dominicana. Río de Janeiro: Conpanhia brasileira de artes gráficas, 1945, pp. 257-258, 
Tratado de moral donde presenta al americano como quien dio el mejor ejemplo del "Deber de trabajo", el primer "deber" de una tabla de "Relaciones y deberes sociales" que recuerda el celebrado código moral de Franklin. El ensayo termina con lo que vale por una franca confesión de deuda al Buen Ricardo: "Nosotros acabamos de probar que la virtud no es un esfuerzo penoso, sino simplemente el ejercicio natural de nuestras facultades. Y si alguien lo prueba es el buen Franklin". ${ }^{539}$ No será exageración de parte de su compatriota José A. Balseiro al afirmar que "en toda su obra... vibra el espíritu del genio estadounidense, que advirtió que sólo son capaces de la libertad los pueblos virtuosos".53b

Quizá no haya paralelo más revelador ni más paradójico que el del "austero" Franklin y el "loco" Sarmiento en cuyo nombre se conmemora el Día del Maestro americano. Pocos prohombres latinos subieron tan alto en la escala de la vida, y por un camino de tan variada y rica experiencia desde una humilde cuna provincial hasta la silla presidencial, que aquel pobre de San Juan que ya en 1827, como tendero de profesión, se imaginaba un Cicerón o un Temístocles, o mejor un Franklin, cuya Vida fue el segundo libro - el primero, la de Cicerón por Middleton- que le cayó en las manos y del cual pudo confesar en sus Recuerdos de provincia (1850) “. . . libro alguno me ha hecho más bien que éste. La vida de Franklin fue para mí lo que las vidas de Plutarco para él, para Rousseau, Enrique IV, Mme. Roland y tantos otros. Yo me sentía Franklin; ¿y por qué no? Era yo pobrísimo como él, estudioso como él, y dándome maña y siguiendo sus huellas, podía un día llegar a formarme como él, ser doctor ad honorem como él, y hacerme un lugar en las letras y en la política americana." Ninguno de aquellos que también se hayan dado maña y seguido sus huellas pudo, con más derecho que don Domingo, ofrecer su propia vida como producto personificado del ejemplo y de los ideales de Franklin. Y, sin embargo, nadie se mantuvo tan castizamente hispánico en toda la médula de su

53a Obras completas (La Habana, 1939), XVI, pp. 313-315.

53b "Hostos en Puerto Rico", Hostos, peregrino del ideal (París, 1954), p. 243. 
ser que aquel apasionado y contradictorio abanderado del lógico y moderado yankee.

El buen gaucho americano, tan orgulloso del apelativo "Don yo," admiró a aquel hombre genial del norte en todas las facetas de su múltiple ser: al hombre modesto y sencillo que "tuvo la audacia de presentarse en la corte más fastuosa del mundo con sus zapatos herrados de labriego y sus vestidos de paño burdo";54 al ciudadano prócer, prototipo de los grandes héroes nacionales como Belgrano que "fue a buscar acomodo con la dinastía real para poner término al conflicto, y como Françlin, volvió desesperando de la prudencia y de la previsión humana a activar el Acta de nuestra Independencia" ;55 al científico práctico - cuyo "espíritu experimental y candoroso se ha encarnado en una nación entera" - que merece mención primera entre los de esta América que han levantado "una punta del velo de la misteriosa Isis de la verdad científica... pues Morse y Edison son sólo sus ejecutores testamentarios"; ; $; 6$ y al "Buen Hombre Ricardo", digno compañero de Confucio, Sócrates, Rousseau, "tipo de la beldad moral ... con sus puntos de ironía y de pillería graciosa y astuta," "57 moralista de un sistema de moral que ninguno "había ofrecido hasta hoy enseñanza y modelos al pueblo, a la sociedad en masa, para mejorar su suerte... y ser además ilustres ciudadanos...." ${ }^{8}$

Quien nació maestro de escuela, llevando en alto durante cuarenta años la antorcha con su divisa "Educar al Soberano", no pudo menos de seguir al Buen Hombre Ricardo en su afán de querer compartir con todos sus hermanos los ideales de conducta que le sirvieron como norma de su propia vida y que le hicieron el venerado y popular maestro de aquella y de sucesivas generaciones de americanos. Por eso, Sarmiento quiso

54 V. Ricardo Rojas, El pensamiento vivo de Sarmiento. Buenos Aires: Losada, 1941, p. 84.

55 "Discurso de la bandera". - Inauguración de la estatua de Belgrano, el 24 de septiembre de 1873.

56 "Conferencia sobre Darwin", el 30 de mayo de 1881.

57 "Lectura sobre bibliotecas populares", el 20 de julio de 1883.

58 "Prólogo", El camino de la fortuna o sea Vida y obras de Benjamin Franklin, de Valdés Vergara. 
que la juventud toda aprovechara las bellas lecciones que él mismo aprendió en la Autobiography de Franklin. Ya en $\mathbf{1 8 4 9}$ afirmó que la Vida "debiera formar parte de los libros de las escuelas primarias," porque "alienta tanto su ejemplo, está tan al alcance de todos la carrera que él recorría, que no habría muchacho un poco bien inclinado que no se tentase a ser un Franklincito..." Al mismo tiempo confesó que había acariciado largo tiempo el propósito de "escribir una vida de Franklin adaptada para las escuelas". Pero en el momento de creerse en aptitud de realizarlo, el académico francés Mignet lo efectuó "con un éxito completo, aunque mi plan era diverso, más popular y más adaptable a nuestra situación”. La Vie de Franklin por Mignet salió en 1848. Sarmiento la pidió cuanto antes a Francia y encomendó la traducción a su amigo José María Gutiérrez, la cual fue publicada en Santiago en 1849. Tuvo tal éxito que para 1856 alcanzó una cuarta edición. Años después, Sarmiento inspiró al chileno Francisco Valdés Vergara que publicara, en 1885, su traducción y arreglo de la vida y obra de Franklin para la cual él mismo escribió el prólogo que termina así: "Franklin ha añadido tres preceptos nuevos al viejo Decálogo de la Moral: Trabajo, Orden, Economía, para obtener y asegurar la libertad y la igualdad en la tierra, objeto de toda moral, que viene a ser el método de vivir feliz y hacer felices a los demás".

Interesa destacar que Valdés Vergara se sirvió de varias obras sobre Franklin escritas por el profesor francés Edouard Laboulaye (1811-1883), amigo de Sarmiento y gran admirador de las instituciones públicas americanas, bibliotecas y escuelas, debidas a la energía y al interés de aquellos apóstoles que se llamaban Franklin y Horace Mann. Recuerda Sarmiento en su discurso sobre "Bibliotecas populares," dado en Buenos Aires el 20 de julio de 1883, que "no era sin un pensamiento de realidad histórica" que su amigo Laboulaye bautizó de "Sociedad Franklin" a la agrupación que en 1881 estableció las primeras bibliotecas circulantes de Francia. Poco después, en imitación de las ideas e iniciativa de Laboulaye, se fundó en San Juan, promovido desde Buenos Aires - y seguramente por el mismo Sarmiento aunque no lo confiesa en 
su conferencia- una Biblioteca Franklin, "que existe aunque sin circulación." 59

La conferencia sobre bibliotecas populares dada en 1883 ante una numerosa concurrencia reunida en los vastos salones de la Biblioteca del Municipio de Buenos Aires, sostenida por la Asociación Rivadavia, nos ofrece otro detalle más con que coronar este breve resumen de la veneración que públicamente expresó Sarmiento toda su larga vida por uno de la trilogía de norteamericanos - los otros dos eran, como bien se sabe, Lincoln y Mann-que más nutrieron su notoria yanquifilia. Sarmiento aprovechó la ocasión para rendir un doble homenaje, tributando un merecido recuerdo a la grata memoria de su amigo Laboulaye y un "homenaje de justicia y reconocimiento" a Franklin, "patriarca de las bibliotecas populares [y] un desmentido a las preocupaciones clásicas de la Europa, la cual ha producido... el espíritu yankee." $\mathrm{Y}$ en palabras bien llenas de emoción evoca para sus compatriotas un cuadro en que se ve reflejada en Franklin la auténtica efigie del pueblo norteamericano, pueblo en donde "el buen sentido ha sido elevado con Franklin a institución y título de nobleza ... donde impera el self-made man, en lugar del patentado estudiante," pueblo "que en sus obras ha seguido la huella de su hombre inmortal," pueblo, finalmente, como reiteró en su último discurso en ocasión de una manifestación escolar allá en la Asunción el 30 de mayo de 1887, unos tres años antes de su muerte, pueblo en donde estudió "las causas de su prodigioso desarrollo y la base de sus libertades para aplicarlas... a nuestros países." Y terminó con una afirmación que sólo para aquel anciano yancófilo obstinado tendría sentido trascendental hasta la muerte: "Así se encuentran reunidos en un solo pensamiento

59 Servirá como epílogo a la historia de esta biblioteca la siguiente nota introductoria para el discurso que pronunció Sarmiento sobre "Educación común" cuando un grupo de jóvenes discípulos le rindió homenaje el 15 de febrero de 1881, en ocasión de su septuagésimo cumpleaños: "Ofreciéronle con este motivo un magnifico bronce Barbendienne, reproducción de la notable estatua de Paul Dubois que simboliza la Historia, en la figura de un anciano meditando... dicho bronce, legado a la Biblioteca Franklin de San Juan, desaparecido en el incendio de dicha Biblioteca junto con los libros y obras de arte que pertenecieron a Sarmiento". Grandes escritores argentinos. Buenos Aires: W. M. Jackson, s. f. I, p. 199. 
los dos extremos de la América, contando con que todo el resto siga bien pronto el grandioso movimiento."

El venerable Sarmiento, ya sordo y medio ciego, no pudo o no quiso percibir, empero, que muchos ya no compartían con él la misma fe que a principios de siglo abrigó todo el mundo en el "gran sueño" americano. La amenaza de la fabulosa prosperidad material, que presintió el extravagante Simón Rodríguez, asumía cada día nuevas dimensiones peligrosas. Y si todavía en 1867 Salvador Costanzo pudo expresar confianza en que el mismo código moral de Franklin también pudiera asegurar prosperidad para España, ${ }^{60}$ al mismo tiempo desde allende los Pirineos llegaba la denuncia de Baudelaire atacando el asfixiante materialismo del país de gas como el asesinato del mayor genio poético jamás producido en las Américas. La denuncia del poeta de las Flores del mal pronto tuvo eco en una noticia sobre Poe escrita por el joven poeta Manuel Cano y Cueto para su traducción de las Historias extraordinarias impresas en Sevilla en 1871. Para este nuevo devoto hispánico del malogrado y mal entendido Poe, los Estados Unidos no eran ya "el noble país" del prócer Franklin, sino más bien tierra de polígamos, de inveterados esclavistas, y de idólatras del dólar todopoderoso. Y esta embrutecida tierra tuvo como padre a aquel otro Franklin el "inventor de una moralidad de escaparate, héroe de un siglo sometido al materialismo."

De mucho mayor trascendencia que la acusación apasionada del sevillano Cano y Cueto, fue la actitud del joven nicaragüense recién llegado a Chile a mediados de 1886, es decir, a poco de empezar a circular la nueva Vida de Franklin, en el arreglo de Valdés Vergara y bajo el patrocinio de Sarmiento. Darío vino con una marcada admiración juvenil por aquel autodidacta cuya Ciencia del Buen Ricardo debió leer por primera

60 "Muy ajenos a la politica, a la diplomacia, a todas las malas o buenas formas gubernativas, creemos con el célebre Franklin, que el buen empleo del tiempo es uno de los resortes más poderosos para la prosperidad de los Estados, y muy persuadidos de que en todo lo que exige fuerza y vigor en el terreno práctico, las teorías no son tan provechosas como los ejemplos y los hechos, vamos a hablar de la economía y del buen empleo del tiempo en Inglaterra". El globo ilustrado (Madrid). I (1867), pp. 242-243. 
vez en 1883 en la Biblioteca Nacional de Nicaragua donde devorara todo libro, inclusive los tomos de la BAE, que allí había. Sobran referencias en la obra de su primera época, anterior a la chilena, para probar tal afirmación. Cuando en su poema "A Víctor Hugo," escrito probablemente por 1883, pide el significado de la palabra "progreso," evoca la anticipada imagen del Franklin "olímpico":

es Franklin con el rayo entre las manos con la frente rodeada de centellas...61

Y un año después, en "El poeta a las musas", escrito el 30 de septiembre de 1884, ha de evocar la misma imagen:

Hoy el rayo de Júpiter Olímpico

Es esclavo de Franklin y de Edison. ${ }^{62}$

Otra, y más significativa, empero, es la imagen evocada por la actitud del joven ya consciente de su propio valer, revelada en las mismas frases iniciales del cuento "Las albóndigas del coronel", publicado en El mercado de Managua el 14 de diciembre de 1885 :

Cuando y cuando que se me antoja he de escribir lo que me dé mi real gana; porque a mí nadie me manda, y es muy mía mi cabeza y muy mías mis manos. Y no lo digo porque se me quiera dar de atrevido por meterme a espigar en el fertilísimo campo del Maestro Ricardo Palma; ni lo digo tampoco porque espere pullas del Maestro Ricardo Contreras. Lo digo sólo porque soy seguidor de la Ciencia del buen Ricardo. Y el que quiera saber cuál es; busque el libro; que yo no he de irla enseñando así no más, después que me costó trabajillo el aprenderla.

Con tan determinada confianza en sí mismo, confianza adquirida indudablemente en el libro del "self-made" yankee, el poeta salió de su Nicaragua natal, "con una estrella en la mano," para despertar desilusionado en una tierra donde reinaba el "Rey Burgués" sobre un pueblo que se ufanaba de ser los "yankees" de la América del Sur. Rubén no pudo ajustarse a las normas de una vida dictada por la Orden, el Progreso, el

61 Obras completas. Madrid: Aguilar, 1952, pp. 200-201.

62 Ibid., p. 357. 
Trabajo y el Sport. Quiso ganarse la vida con la pluma, pero no pudo continuar como los demás "strugleforlíferos de la prensa", contribuyendo con crónicas sobre el "sport" para un "diario de modelo yankee, El ferrocarril","3 cuando lo que más deseaba, era "dar al viento la palabra soñadora, el oropel del estilo 'decadente' ...," es decir, lo "azul" de una nueva expresión inspirada en "la inédita y deslumbrante concepción del estilo" de Gautier, de Mendès y de otros franceses cuyas páginas leyó por primera vez en las nutridas bibliotecas de los cresos chilenos. Darío no pudo creer más, con el optimismo del poeta-niño centroamericano, en la doctrina de la perfectibilidad del individuo cuando aquel mismo código moral profesado por Franklin pareció haber creado una mediocridad burguesa en donde el ser no tuvo otro recurso sino conformarse- o morir de hambre como el poeta de sus cuentos de $A z u l$. No pudo concordar con esos chilenos que aprobaron preceptos morales cuyo "único apoyo o cimiento [según su interpretación de Franklin] era el de la utilidad humana verificada por las consecuencias benéficas que su aplicación a la conducta producirían"64 ni aceptar que la prosperidad terrenal-la cual el pueblo chileno bien podría realizar mediante las enseñanzas encerradas en la Vida de Franklin- "debe ser uno de los secretos anhelos de todo espíritu sano i juicioso." 65

La reacción de Darío contra la moralidad materialista de la época se hizo patente en la nota satírica e irónica que empezó a caracterizar algunas obras escritas ya en 1887. Véanse tan sólo los versos "Aviso del porvenir," publicados en $L a$ época de Santiago, el 24 de marzo de 1887. El final parece de una intención indiscutible:

\section{¡Atención! ¡Atención! Se abre una fábrica de buenos sentimientos. iAtención!}

63 Sabido es, claro está, que Rubén escribió una serie de ocho "Semanas" para $E l$ beraldo de Valparaíso. Fue la penúltima de éstas, aparecida el 7 de abril de 1888 , que dedicó, aparentemente por obligación y después de un día de carreras en el Hipódromo de Viña del Mar, a un pot-pourri sobre los deportes.

64 V. Eduardo Lamas G., "Benjamín Franklin", La revista de Chile, V (1900), 8, pp. 244-248; 9, pp. 268-272. Este artículo de Lamas es una reseña de la segunda edición de la Vida de Valdés Vergara publicada aquel mismo año en Valparaiso.

65 Loc. cit. 


\begin{abstract}
¡Acudid! ¡Acudid! La ciencia hipnótica le ha tocado las barbas al buen Dios. Procedimientos de excelentes médicos, pueden hacer sentir a un corazón

en un minuto o dos, a precios módicos, lo que guste el feliz consumidor. Pueden hacerse los bandidos ángeles como se hacen tortillas con jamón, y se dan pasaportes baratísimos para ir al reino celestial, by God! Se hacen almas virtuosas y magníficas de cuarenta caballos de vapor, y lecciones se dan teórico-prácticas para vencer a Lucifer al box. Yo, señores, me llamo Peter Humbug (obsecuente y seguro servidor), y me tienen usted a sus órdenes, 30, Franklin Street, en Nueva York.
\end{abstract}

La ironía de la penúltima "Semana," que salió el 7 de abril de 1888, es característica ya de la rebelión que rápidamente se estuvo plasmando por todo el mundo occidental:

¡Qué cambio! La raza latina de antes, tan vigorosa, $\tan$ atlética, tan llena de pujanza, y la de hoy tan canija, tan debilitada, tan sin músculos, toda entregada a utopías, toda dolorosa, toda decadente.

Porque -iDios santo! - vamos quedando con nuestro modo de ser americanizados por la raza férrea anglo-sajona, al menos en América, raza que ha hecho de sus puños martillos, que habla una lengua férrea también, ruda, erizada, rápida y casi eléctrica. ${ }^{66}$

Tres meses después, esta nota se hizo dominante en las páginas de $A z u l$, primer grito de protesta consciente de los modernistas en cuyo escudo poético el cisne "de engañoso plumaje" dio el mentís al lema frankliniano: "Abandona toda ocupación que no produzca nada."

Lanzada en las alas del inmaculado cisne, la protesta de los modernistas se hizo continental e hispánica en la ideología

66 Raúl Silva Castro. Obras desconocidas de Rubén Dario. Santiago: Prensas de la Universidad de Chile, 1934, p. 158. 
de Ariel (1900), nueva Biblia de todos los que denunciaron “el triunfo de Calibán." 67 En la revalorización de las ideas e ideales que fue inevitable con la bancarrota de la Ciencia y la Razón, los extremistas, encabezados por D. H. Lawrence, se negaron a aceptar como norma de conducta y de carácter el evangelio del "buen éxito", que para mejor o peor, se convirtiera en la religión social de los tiempos modernos. Para ellos "el viejo Papá Franklin ... cercó un pequeño terreno, al que llamó el alma del hombre y procedió a cultivarlo." Le acusaron de haber colocado "un alambrado de púa" alrededor del espíritu, intentando convertir al hombre "en un pequeño autómata virtuoso." Aplaudieron la protesta de Lawrence: "Soy un animal moral. Pero no soy una máquina moral." $\mathrm{Y}$, finalmente, para desacreditarle por completo ante el hombre-masa actual, formularon un credo opuesto, invirtiendo sistemáticamente los consagrados preceptos de Franklin. La Ciencia del Buen Hombre Ricardo acabó por ser clasificada con la barata literatura moralista de los Smiles, Marden, Trine, y Carnegie. ${ }^{68}$ El "Platón Casero" también pasó a un plano definitivamente histórico.

67 "No, no puedo, no quiero estar de parte de esos búfalos de dientes de plata. Son enemigos míos, son los aborrecedores de la sangre latina, son los bárbaros. Así se estremece hoy todo noble corazón, así protesta todo digno hombre que algo conserve de la leche de la Loba... El ideal de esos calibanes está circunscrito a la bolsa y a la fábrica... Enemigos de toda idealidad, son en su progreso apoplético, perpetuos espejos de aumento; pero Sir Emerson bien calificado está como luna de Carlyle; su Whitman con sus versículos a hacha, es un profeta demócrata, al uso de Tío Sam; y su Poe, su gran Poe, pobre cisne borracho de pena y de alcohol, fue el mártir de su sueño en un país en donde jamás será comprendido... No, no puedo estar de parte de ellos, no puedo estar por el triunfo de Calibán... Por eso mi alma se llenó de alegría la otra noche, cuando tres hombres representativos de nuestra raza fueron a protestar en una fiesta solemne y simpática, por la agresión del yankee contra la hidalga y hoy agobiada España". Rubén Darío, "El triunfo de Calibán", El tiempo (Buenos Aires), 20 mayo 1898. Los "tres hombres representativos" eran Roque Sáenz Peña, Groussac, y Tarnassi. Reconocido es que esta actitud fogosa de parte de Dario responde más bien a la ocasión; no representa una posición inequívoca frente a los Estados Unidos.

68 Los evangelios de estos moralistas han sido traducidos y leídos en infinitas ediciones por todo el mundo hispánico hasta nuestros días. Notoria ha sido la popularidad del último de estos evangelistas del "buen éxito". Vale observar que 
Epitafio.

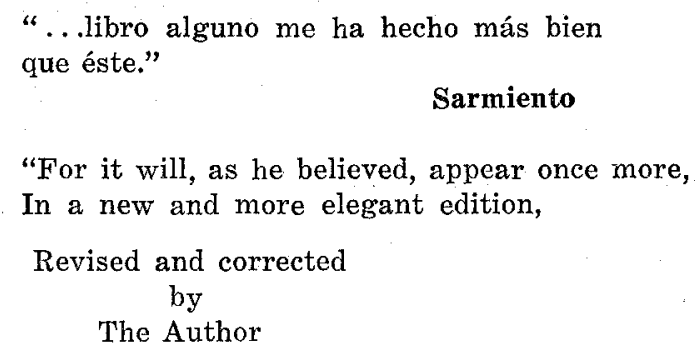

\section{Franklin}

El negar que la palabra de Franklin tenga significado para el mundo de hoy sólo puede tener validez, empero, si se insiste únicamente en ver el retrato del Franklin legendario y estereotipado del mito popular. El doscientos cincuenta aniversario de quien ha sido aclamado como uno de los creadores de la tradición americana brindó la oportunidad de estudiar el reverso de la medalla. Muchos han intentado descubrirle de nuevo en la prístina claridad de sus obras. $Y$ a éstos les ha sido permitido apreciar a Franklin una vez más tanto como uno de los grandes científicos de los tiempos modernos como uno de los más ingeniosos inventores de su época; tanto como el precursor de los grandes benefactores públicos de hoy como el ilustre prócer nacional de ayer; y tanto como el filósofo astuto que supo vivir intensamente el momento actual - "No pierdas el tiempo; dedícate siempre a algo útil; no realices ningún acto innecesario," sin dejarse jamás engañar por las apariencias - como el sano "Platón casero" que supo respetar las creencias morales de su siglo e incorporarlas en un libro que sirvió para moldear la vida y el carácter de millones de jóvenes de generaciones pasadas, séanlos de los "prairies"donde se

el libro clásico del género, Cómo ganar amigos e influir sobre las personas de Dale Carnegie (1888-1955) pasó por ocho ediciones en cuatro años únicamente en la traducción de la Editorial Sudamericana de Buenos Aires. $\mathrm{Y}$ en la versión portuguesa de la Editora Nacional de Río y Lisboa alcanzó doce ediciones en seis años. Ningún otro libro americano, en plazo tan breve, ha gozado de tanto éxito en la patria grande de Cervantes y Camoens. V. mis estudios, Bibliografia de obras norteamericanas en traducción española. México, 1944, pp. 79, 92-94, 104, y $A$ litęratura norteamericana no Brasil, pp. 142, 151-152. 
recitaba en inglés, séanlos de la pampa donde se aprendía a ser un "Franklincito" bajo el tutelaje del joven maestro Sarmiento.

El mundo hispánico participó plenamente en el homenaje universal a Franklin. De una de las más bellas y más dignas de estas conmemoraciones americanas surgió un nuevo aprecio de Franklin que ha de perdurar como válido por haberse sabido interpretar y captar el verdadero y pleno sentido de su mensaje : 69

Nuestra época y las generaciones venideras perciben y verán siempre en Franklin un símbolo de progreso, de perfección humana, de amor a la verdad, y de entrega en favor del bienestar de las nuevas y viejas colectividades. Recogemos de él, al mismo tiempo, el más generoso y sabio mensaje de fraternidad, de solidaridad y paz mundial.

\section{B I B L I O G R A F I A}

I. Obras de Franklin en Traducción Española.

"Letter to Miss Mary Stevenson" (20 septiembre 1761).

"Estracto de una carta del Sr. Francklin a Miss Stevenson, acerca de los esperimentos relativos al calor que comunican los rayos del sol". Gaceta de literatura de México, 13 diciembre 1790, pp. 77-79. Trad. José Antonio Alzate Ramírez. Reimpreso en Gacetas de literatura de México (Puebla: Oficina del hospital de San Pedro, 1831), II.

"Letter to Lord Kames" (2 junio 1765).

"Esperimentos de Francklin acerca de la sensación que los ópticos reciben de los objetos luminosos". Gaceta de literatura de México, 13 diciembre 1790, pp. 79-80. Trad. José Antonio Alzate Ramírez. Reimpreso en Gacetas de literatura de México. II.

"Letter to Miss Mary Stevenson" (13 septiembre 1760).

69 Homenaje del Instituto Cultural Peruano-Norteamericano, IPNA, 29 (1955), p. 3. 
"Acerca de ciertas olas muy particulares". Gaceta de literatura de México, 13 diciembre 1790, pp. 80-81. Trad. José Antonio Alzate Ramírez. Reimpreso en Gacetas de literatura de México. II.

"Letter to William Brownrigg" (7 noviembre 1773).

"Compendio de una carta del Dr. Francklin, escrita al Dr. Brownrigg" (del aceite sobre el agua turbulenta). Gaceta de literatura de México, 11 y 25 enero 1791. Trad. José Antonio Alzate Ramírez. Reimpreso en Gacetas de literatura de México. II, pp. 98-103.

"Letter to Joseph Priestley" (de fecha no determinada).

"Respuesta del Dr. Francklin al Dr. Presley" (sic) (del poder que tienen los vegetales para purificar el aire que corrompen los animales). Gaceta de literatura de México, 3 mayo 1791. Trad, José Antonio Alzate Ramírez. Reimpreso en Gacetas de literatura de México. II, pp. 174-175.

(Artículo de Franklin extractado de las memorias del Abate Rochon).

"Método de Mr. Francklin para imprimir con la misma velocidad que se escribe, estractado de las memorias acerca de la mecánica y física, por el Abate Rochon". Gaceta de literatura de México, 14 junio 1791. Trad. José Antonio Alzate Ramírez. Reimpreso en Gacetas de literatura de México. II, p. 204.

"Letter to John Lining" (17 junio 1758).

"Segunda carta del Sr. Franklin acerca del frío que se esperimenta por la evaporación de los licores". Gaceta de literatura de México (de fecha no bien determinada; entre 9 y 23 abril u 11 y 28 mayo 1793). Trad. José Antonio Alzate Ramírez. Reimpreso en Gacetas de literatura de México. III, pp. 128-136.

Autobiography (1791-francés; 1793 -inglés).

Vida del Dr. Benjamín Franklin. Madrid: Pantaleón Aznar, 1798, XX -216 p. Ils. "Sacada de documentos auténticos". Portada grabada con el retrato de Franklin. Trad. y arreglo de Pedro Garcés de Mancilla. 
Vida de Franklin. Santiago de Chile: Julio Belín, 1849, 226 p. Trad. de la Vie de Franklin (1848) de François A. Mignet (1796-1884), por Juan María Gutiérrez; ibid., 1850, VI-226 p.; ibid., 1853, 155 p.; ibid. Valparaíso: Santos Tornero, 1856. Citada en el "Catálogo de los libros i folletos impresos en Chile desde que se introdujo la imprenta (18121858)", Revista de ciencias y letras (Santiago). I (abril 1858), pp. 739-768.

Vida de Franklin, en Gaceta de Santander, 1861. Trad. -o arreglo- de Adriano Páez. Citada por Isidro Laverde Amaya, Apuntes sobre bibliografía colombiana (1882), p. 76. El camino de la fortuna o sea vida y obras de Benjamin Franklin. Santiago: "Cervantes", 1885, 336 p. Trad. y arreglo de Francisco Valdés Vergara, a base de una o más obras de Edouard Laboulaye (1811-1883) sobre Franklin. Retrato de Franklin. Prólogo de Sarmiento. Apéndice: "La Caja de Ahorros de Santiago", pp. 327-330; Vida de Benjamín Franklin. $2^{a}$ ed. Valparaíso: Litografía e Imprenta Sud-Americana de Barra y Cía., 1900, 338 p. Con retrato; "Franklin y la Independencia de los Estados Unidos" (extracto), IPNA, 29 (septiembre-diciembre 1955), pp. 39-43.

Autobiografía de Benjamin Franklin. Boston-New York: D. C. Heath, s. f. (ca. 1916), XVIII-422 p. Ils. Con trozos ascogidos de sus obras, con notas críticas y modelos para la enseñanza. Trad. M. R. Blanco-Belmonte. Vocabulario en inglés y español por Alfredo Elías. ("Clásicos literarios en inglés de Heath").

Franklin. Madrid: Pueyo, 1919, 237 p. Trad. de la Vie de Franklin (1848) de François A. Mignet, y prólogo, por Mario García Kohly; -2 2a ed., 1919.

Benjamin Franklin. Relatada a los niños. Santiago: Ercilla, s. f., 84 p. Trad. y arreglo de José Baeza. (Juvenil Ercilla: $\mathrm{I}, 7)$.

Autobiografía y otros escritos. México: Nuevo Mundo, 1942, 464 p. Trad. León-Felipe. Selección y arreglo de Carl Van Doren. (Biblioteca Moderna: 1).

Autobiografía y otros escritos. Barcelona: Iberia, 1954, XI-230 p. Trad. Manuel Scholz Rich. Prólogo Emiliano M. Aguilera. 
"The whistle" (1779).

"Benjamin Franklin's Whistle". Semanario de agricultura, industria y comercio (Buenos Aires), 90 (6 junio 1804). (Artículo no identificado).

"Luxury, laziness and work". Semanario de agricultura, industria y comercio (Buenos Aires), 116 (5 diciembre 1804). (Artículo no identificado).

"Note on how to make people enjoy work". Semanario de agricultura, industria y comercio, 125 (6 febrero 1805).

"The art of procuring pleasant dreams" (1786).

"The art of having pleasant dreams," Semanario de agricultura, industria y comercio, 179 (19 febrero 1806).

"Rules by which a great empire may be reduced to a small one" (1773).

"Reglas para convertir en pequeño un estado grande, presentadas a un ministro británico en el año de 1774". El sastre constitución (México), 18 julio 1820.

Poor Richard's Almanac (1733-1758).

Miscelánea de economía, política y moral_Precedida de una noticia sobre la vida del autor. París: C. Farcy, 1825, 2 tomos, 238 y 226 p. Trad. del francés por R. Mangino.

"Discurso de Ricardo Saunders" (a la cabeza de su almanaque de 1757). Almanaque para el año 1829, $X X$ de nuestra Libertad. Buenos Aires: Imprenta de la Independencia, 1829.

"El camino de la fortuna, o Como dice el Compadre Ricardo". Semanario pintoresco (Madrid), 5 (1 mayo 1836).

"Moral privada. Plan ideado por Benjamín Franklin para arreglar su vida". Semanario pintoresco, 26 (16 junio 1842).

El libro del hombre de bien. Opúsculos morales, económicos y políticos extractados de Benjamín Franklin. Barcelona: A. Bergnes, 1843; ibid., 1867.

Ciencia del Buen Ricardo, precedida de una noticia de su vida. Madrid: Unión Comercial, 1844.

"Máximas" y "Pensamientos". El prisma (Habana). I (1846), 129-130 ss. 
"Consejos de Franklin". La ilustración (Madrid), 8 diciembre 1849.

La ciencia del Buen Ricardo o El camino de la fortuna. Caracas: G. Corser, 1858, 48 p. Seguido de un artículo por J. M. Samper, "Pensamientos sobre moral, política, literatura, religión y costumbres".

"Consejos del Buen Ricardo", Almanaque-aguinaldo de la Isla de Puerto Rico para el año bisiesto de 1860. Puerto Rico: Imprenta de Acosta, s. f. (1860), pp. 104-106; ibid., 1861, pp. 125-128.

Miscelánea de economía política y moral. New York: Casa de Vingut, 1864, 2 tomos.

"Máximas de Franklin". El siglo ilustrado (Madrid), 22 marzo 1868.

La economía política puesta al alcance de los niños. Buenos Aires: Pablo E. Coni, 1873, 206 p. Trad. Otto Hübner. "Versión castellana para el uso de las escuelas de la República Arjentina... Con un apéndice conteniendo varios opúsculos de Benjamín Franklin".

Ricardo o ciencia de hombre de bien. Trad. en verso por Enrique Seoane, según Constantino Carrasco, en El correo del Perú (Lima, diciembre 1874. Nota de Estuardo Núñez, "Franklin en América hispana", p. 19.

"La ciencia del Buen Hombre Ricardo". El educador popular (New York). IV (1876), pp. 81, 113.

La ciencia del buen hombre Ricardo. Guayaquil: "La nación", 1879, 76 p. Precedida de un compendio de la vida del autor.

El libro del hombre de bien. Leipzig, 1882. Trad. J. Abelardo Núñez. V. Estuardo Núñez, "Franklin en América hispana", p. 16.

Ciencia del buen Ricardo. Barcelona: Juan Pons, s. f. (ca. 1890).

Ofrenda a los artesanos. Benjamín Franklin. El arte de hacerse rico. Managua: Tipografía Nacional, 1897, VI-202 p. Prólogo: "A los artesanos de Centro-América" por Genaro Lugo, pp. V-VI.

Manual del demócrata peruano y conducta del hombre de 
bien. Lima: "El país", 1897, 102 p. La segunda parte del folleto se titula "Opúsculos de Benjamín Franklin tomados de su obra titulada: El libro del hombre de bien". Los opúsculos son: "Plan de mejora social", "Advertencias a los que quieren ser ricos", "Consejos a un joven jornalero", "Medios para tener siempre dinero en el bolsillo", y "La ciencia del Buen Ricardo o El camino de la fortuna".

La ciencia del buen Ricardo. Bogotá: Librería Nueva, s. f. (ca. 1900). (Biblioteca Popular: 149. Editor: Jorge Roa).

“Máximas" y "Frases". Arte y letras (México), 11 abril 1909, p. 20, y 26 diciembre 1909, p. 15; El mosaico mexicano. I, p. 419; El museo mexicano. III, pp. 272, 287; Revista de revistas (México), 19 junio, 18 septiembre, 30 octubre 1938; y 5 marzo, 16 abril, 4 junio, 18 junio 1939.

El camino de la fortuna o La ciencia del buen Ricardo. Bahía: "El globo", 1922, 8 p.

"Proverbios de Franklin". Revista Ariel (Tegucigalpa). II (30 junio 1926), p. 572.

El libro del hombre de bien. Madrid: Espasa-Calpe, s. $\mathbf{f}$. (ca. 1931). (Nueva Biblioteca Filosófica: 36).

"Frases de Franklin". Ariel (San José, C. R.). XXV (15 septiembre 1940), p. 1861.

El libro del hombre de bien. Buenos Aires: Espasa-Calpe, 1941, 186 p. (Colección Austral: 171).

"Máximas de Benjamín Franklin". Libro de lectura panamericano. Bogotá: Editorial Santafé, 1944, pp. 64-65. Editor: Julio C. Gaitán.

"El pobre Ricardo — Sentencias escogidas". IPNA (Instituto Cultural Peruano-Norteamericano). 29 (septiembre-diciembre 1955), p. 58-61.

(Artículo no identificado).

"El préstamo de Franklin". Semanario pintoresco, 30 julio 1837.

Traducciones no identificadas, en El Plata (Buenos Aires), 1854-1855. 
(Artículo no identificado).

"Memorial de la mano izquierda". Almanaque-aguinaldo de la Isla de Puerto Rico, 1875, pp. 54-55.

"A parable on brotherly love" (1774).

"Parábola sobre el amor". El cojo ilustrado (Caracas). I (15 abril 1892), p. 115; ibid., Revista de revistas (México), 25 febrero 1912, p. 9.

(Artículo no identificado).

"De los cambios de posición". El cojo ilustrado. II (15 junio 1893), p. 219.

(Artículo no identificado).

"Elogio del vino". El cojo ilustrado. XVI (15 julio 1907), p. 430 .

(Artículo no identificado).

"Apólogo". Hispano-América (Tegucigalpa). I (1 noviembre 1923).

(Epitafio de Franklin).

"Epitafio de Franklin". Ariel (San José, C. R.). V (1 abril 1938), p. 443.

"Speech on the Constitution of the United States (1787).

"El voto de Franklin". América (Habana). VIII (noviembre 1940), p. 33; "Discurso sobre la Constitución de los Estados Unidos". IPNA. 29 (septiembre-diciembre 1955), pp. 56-57.

(Artículo no identificado).

"La guerra", Libro de lectura paanamericano (Bogotá, 1944), p. 127.

II. Obras de Franklin en Traducción Portuguesa.

Poor Richard's Almanac (1733-1758).

$A$ ciência do bom Ricardo e outras obrinhas de Benjamin Franklin. Lisboa: Imprenta Nacional, 1856, 30 p.

A ciencia do bom homem Ricardo. Rio: Tipografía de Peixoto, $1859,21 \mathrm{p}$. Trad. y prólogo: M. V. Ferreira.

A ciência do bom homem Ricardo - Conselhos para fazer fortuna, en Verdades economicas ou $A$ riqueza ao alcance de 
todos. Lisboa: A. M. Pereira, 1876, 245 pp. Trad. y prólogo: Miguel Augusto da Silva.

A ciência do bom homem Ricardo ou O caminho da fortuna. Rio: Livraria Nicolau-Alvea, 1884, $21 \mathrm{p}$.

A ciência do bom homem Ricardo ou méios de fazer fortuna. Rio: Laemmert, s. f. (ca. 1901), 30 p. Prólogo: A. J. S. (editor francés). (Biblioteca das Folhinhas Laemmert: 13).

Aforismo doméstico para legítimos constitucionaes, ou Ciência do bom homem Ricardo dando um méio fácil para pagar tributos. Rio: Imprenta Nacional, s. f.

Breviário do homem de bem. Rio: Vecchi, 1943, 125 p. Trad. Dírio Gorgot. (Os Grandes Pensadores: 7 ).

III. Crítica Española.

Alzate Ramírez, José Antonio. "Breve elogio de Benjamín Franklin", Gaceta de literatura de México, 13 diciembre 1790, pp. 74-77; reimpreso en Gacetas de literatura de Mém xico. Puebla: Oficina del Hospital de San Pedro, 1831.

Anónimo. "Benjamín Franklin", El apuntador (México). I (1841), pp. 225-227. Artículo biográfico. Reproduce el "Epitafio".

Anónimo. "Anécdota de Franklin", "El museo mexicano. I (1843), p. 543.

P (irala), A (ntonio). "Franklin", Revista histórica (Madrid). I (1851), pp. 295-296. Foto-medalla. Breve aprecio y poema "A Franklin".

Anónimo. "Benjamín Franklin", La abeja (México), 20 enero 1875, p. 7. Artículo biográfico.

Olmedilla y Puig, Joaquín. "Franklin", Revista europea (Madrid). VII (18 junio 1876), pp. 638 ss. Sobre las investigaciones de Franklin relativas a al electricidad.

Rodó, José Enrique. "Benjamín Franklin”, Lo cierto y nada más (1883), revista estudiantil redactada por Rodó, que duró tres números; amplificado y reimpreso en otra revista suya Los primeros albores. I (23 julio 1883), que también duró sólo tres números. 
Sarmiento, Domingo Faustino. "Prólogo", El camino de la fortuna o sea vida y obras de Benjamin Franklin (Santiago, 1885), por Francisco Valdés Vergara; $-2^{\natural}$ ed. 1900; "Semblanza de Franklin", IPNA, 29 (septiembre-diciembre 1955), pp. 36-38.

Lamas G., Eduardo, "Benjamín Franklin", La revista de Chile. V. (15 octubre 1900), pp. 244-248, 1 (noviembre 1900), pp. 268-272. Larga reseña de la segunda edición de la obra de Valdés Vergara.

Courrier, P. L. "Franklin y su folleto 'Buen sentido'", La semana (Caracas). V (1905-1906), 199, pp. 189-191.

Wiesse, Carlos. "Franklin, profeta de la libertad", Prisma (Lima). 22 (septiembre 1906); -IPNA. 30 (eneroabril 1956), pp. 16-17. Resalta "la faceta del constructor democrático de los EE. UU., proponiéndolo como paradigma para los pueblos del continente".

Anónimo. "Héroes de la ciencia. Benjamín Franklin". Páginas ilustradas (San José, C. R.). III (2 diciembre 1906), pp. 1975-1976.

Mayorga Rivas, Ramón, "Tumba de Franklin", Viejo $y$ nuevo. San Salvador, 1915. Poema.

"Tumba de Franklin"

(En Philadelphia)

No se alza aquí soberbio monumento;

que deslumbre al mortal con su riqueza, en una humilde losa tiene asiento

sólo un nombre, y no más. Tanta grandeza

a sí misma se basta, y la rodea

atmósfera sagrada en que se agita

la vida universal; aquí palpita

todo lo grande que a los genios crea.

Qué mejor homenaje? El sol radiante es lámpara encendida a su memoria, el firmamento es dombo de su gloria, y el planeta su altar. Natura amante, 


\begin{abstract}
prodiga aquí sus cantos y sus flores y ante él su augusta magestad humilla; y el hombre, puesta en tierra la rodilla, le tributa el mayor de los honories.
\end{abstract}

Avella Mendoza, Temístocles. "El espíritu de Franklin", Labor intelectual. Bogotá: Tipografía Mercantil, 1915, pp. 61-65. Artículo biográfico, y de alto elogio, con traducciones de preceptos del filósofo "exento de toda preocupación".

Baeza, José. Benjamin Franlin, obrero, politico, escritor, inventor, su vida ejemplar, relatada a los niños. Barcelona: Araluce [1928], 149 p. (Los grandes hechos de los grandes hombres).

Santelmo, Jorge, Vida de Benjamín Franklin. $3^{\text {a }}$ ed. Barcelona, I.G. Seix \& Barral, 1930, 102 p. (Vidas de grandes hombres).

Nicolay, Helen. Benjamín Franklin. Santiago: Zig-Zag, 1937, 311 p. Trad. de The boys' life of Benjamin Franklin (New York: Appleton-Century, 1935), por Consuelo Villanueva.

Anónimo. "Augurio de Franklin", Ariel (San José, C. R.). XIV (15 abril 1939), p. 1047.

Deza Méndez, Gonzalo. "Autobiografía", Revista de Revistas (México), 27 septiembre 1942. Reseña, altamente favorable, de la obra de Carl Van Doren traducida por León-Felipe (1942).

Anónimo. "Franklin". Amigos inolvidables. Buenos Aires: Asociación de difusión interamericana, 1942-1943.

Mejía Sánchez, Ernesto. "Literatura norteamericana: 1. Franklin", El diario nicaragüense (Granada). XXXIV (11 enero 1947), p. 2.

Portuondo, Fernando. "Benjamín Franklin: La autobiografía”. Universidad del Aire (Habana), 3 octubre 1954. Conferencia.

Anónimo. "Vida de Benjamín Franklin", IPNA. 29 (septiembre-diciembre 1955), pp. 51-55. Datos cronológicos.

Anónimo. "El aniversario de Franklin", IPNA. 29 (septiembre-diciembre 1955), pp. 62-64.

Campa, Arthur L. "Benjamín Franklin", IPNA. 29 (sep- 
tiembre-diciembre 1955), pp. 5-9. Artículo biobibliográfico y de aprecio general.

Davis, Harold. "El significado histórico de Benjamín Franklin", IPNA. 29 (septiembre-diciembre, 1955), pp. 49-50. "El llevó la Revolución Americana a Francia y así comenzó el proceso de su universalización".

Erwin, Horace W. "Franklin y Mozart", IPNA. 29 (septiembre-diciembre 1955), pp. 34-35. “... Mozart grabó sus iniciales en el instrumento [armónica] de Franklin".

Infante, Luis C. "Paralelo entre Benjamín Franklin y don Hipólito Unánue”, IPNA. 29 (septiembre-diciembre 1955), pp. 30-33.

Irwin, H. Franklin. "Benjamín Franklin: Infinito en sus facultades", IPNA. 29 (septiembre-diciembre 1955), pp. 4448.

Kahn, Robert L. "Benjamín Franklin y George Forster", IPNA. 29 (septiembre-diciembre 1955), pp. 20-24.

Núñez, Estuardo. "Franklin en América hispana", IPNA. 29 (septiembre-diciembre 1955), pp. 10-19; "Franklin en Hispanoamérica", Cuadernos americanos. 88 (1956), pp. 155-168.

Onís, José de. "Benjamín Franklin ciudadano de América”, IPNA. 29 (septiembre-diciembre 1955), pp. 25-27. "Hoy, que vemos una vez más esa misma cultura puesta en prueba por el amanecer de otros valores, Benjamín Franklin, y los ideales que él representó para nuestros abuelos, lejos de haber perdido su vigencia, son cada día más dignos de nuestro interés y estudio".

Valle, Rafael Heliodoro. "Dimensión de Franklin", IPNA. 29 (septiembre-diciembre 1955), pp. 28-29.

Bosch, Santos. Benjamin Franklin. Barcelona: Ediciones G. P., 1955, 64 p. (Enciclopedia Pulga: 104).

Chase, Gilbert. "Franklin y la música", IPNA. 30 (eneroabril 1956), pp. 3-11. Capítulo de su obra sobre La música en los $E E$. $U U$., de próxima publicación en castellano.

McCloskey, Richard. "Benjamín Franklin, impresor", IPNA. 30 (enero-abril 1956), pp. 12-13.

Williams, Stanley T. "Franklin y Latino-América", IPNA. 
30 (enero-abril 1956), pp. 14-15. Apuntes sacados de su obra sobre The Spanish Background of American Literature.

Valbuena Briones, Angel. "Benjamín Franklin, personaje humano", Arbor. 124 (1956), pp. 569-575. Sobre las diversas facetas de su genio y personalidad.

IV. Crítica Portuguesa.

Van Doren, Carl. Benjamín Franklin. Porto Alegre: Globo, 1943, 596 p. Trad. de Benjamín Franklin (New York: Viking, 1938) por J. de Matos Ibiapina.

Amzalak, Moses Bensabat. Benjamin Franklin, economista. Lisboa, 1941, 122 p. Foto.

- Silva, Agostinho da. Vida de Franklin. Vila Nova de Famalição: "Minerva", 1942, 117 p.

JOHN E. ENGLEKIRK.

Tulane University, New Orleans, Louisiana. 
